\title{
Assessment of Rice Growth Conditions in a Semi-arid Region of India Using the Generalized Radar Vegetation Index Derived from RADARSAT-2 Polarimetric SAR Data
}

\author{
Dipankar Mandal ${ }^{\mathrm{a}, *}$, Vineet Kumar ${ }^{\mathrm{a}}$, Debanshu Ratha ${ }^{\mathrm{a}}$, \\ Juan M. Lopez-Sanchez ${ }^{\mathrm{b}}$, Avik Bhattacharya ${ }^{\mathrm{a}}$, Heather McNairn ${ }^{\mathrm{c}}$, \\ Y. S. Rao ${ }^{\mathrm{a}}$, K. V. Ramana ${ }^{\mathrm{d}}$ \\ ${ }^{a}$ Microwave Remote Sensing Lab, Centre of Studies in Resources Engineering, \\ Indian Institute of Technology Bombay, Mumbai, India \\ ${ }^{b}$ University Institute for Computing Research, University of Alicante, Spain \\ ${ }^{c}$ Ottawa Research and Development Centre, Agriculture and Agri-Food Canada, Canada \\ ${ }^{d}$ Agriculture Sciences and Application Group, National Remote Sensing Centre, Indian \\ Space Research Organisation (ISRO), India
}

\begin{abstract}
Rice growth monitoring using Synthetic Aperture Radar (SAR) is recognized as a promising approach for tracking the development of this important crop. Accurate spatio-temporal information of rice inventories is required for water resource management, production risk occurrence, and yield forecasting. This research investigates the potential of the proposed Generalized volume scattering model based Radar Vegetation Index (GRVI) for monitoring rice growth at different phenological stages. The GRVI is derived using the concept of a geodesic distance (GD) between Kennaugh matrices projected on a unit sphere. We utilized this concept of GD to quantify a similarity measure between the observed Kennaugh matrix (representation of observed Polari-
\end{abstract}

\footnotetext{
*Corresponding author: Dipankar Mandal (dipankar.agrilengg@gmail.com)
} 
metric SAR information) and the Kennaugh matrix of a generalized volume scattering model (a realization of scattering media). The similarity measure is then modulated with a factor estimated from the ratio of the minimum to the maximum GD between the observed Kennaugh matrix and the set of elementary targets: trihedral, cylinder, dihedral, and narrow dihedral. In this work, we utilize a time series of C-band quad-pol RADARSAT-2 observations over a semi-arid region in Vijayawada, India. Among the several rice cultivation practices adopted in this region, we analyze the growth stages of Direct seeded rice (DSR) and conventional Transplanted rice (TR) with the GRVI and crop biophysical parameters viz., Plant Area Index - PAI. The GRVI is compared for both rice types against the Radar Vegetation Index (RVI) proposed by Kim and van Zyl. A temporal analysis of the GRVI with crop biophysical parameters at different phenological stages confirms its trend with the plant growth stages. Also, the linear regression analysis confirms that the GRVI outperforms RVI with significant correlations with PAI $(r \geq 0.83$ for both DSR and TR). In addition, PAI estimations from GRVI show promising retrieval accuracy with Root Mean Square Error (RMSE) $<1.05 \mathrm{~m}^{2} \mathrm{~m}^{-2}$ and Mean Absolute Error (MAE) $<0.85 \mathrm{~m}^{2} \mathrm{~m}^{-2}$.

Keywords: Rice, GRVI, SAR Polarimetry, direct seeded rice, RVI

\section{Introduction}

2 Rice (Oryza sativa) is the major crop grown in the Indian subcontinent of 3 Asia. The majority of the rice cultivars are grown during the monsoon season 4 (July to November), i.e., Kharif season. Despite available rain, in many 5 regions, rice production is significantly affected by the early or late arrival of 
monsoon. In particular, farmers have been cultivating rice for decades in the rainfed regions of the Krishna and Guntur districts of India which fall under the semi-arid climatic zone. However, instead of traditional transplanted rice cultivation practices, direct seeding of rice is gaining attention and is being promoted under Integrated Crop Management (ICM) government policies in the semi-arid region of these districts (APAgriculture, 2018; NIBIO, 2012).

Rice production strongly depends on the crop establishment period, which affects the critical phenological stages (tillering, flowering, and grain filling periods) Mahajan et al., 2009; Lampayan et al., 2015). Thus, it is essential to monitor the temporal dynamics of plant growth over a large spatial extent. Despite promising results reported from optical remote sensing, the implementation of optical sensing for mapping and monitoring of rice during the monsoon season is problematic given the persistent presence of clouds. As such, the exploitation of Synthetic Aperture Radar (SAR) has drawn considerable attention for rice monitoring in the monsoon season, given the ability of microwaves to acquire data regardless of cloud cover and the sensitivity of SAR signal to dielectric and geometric properties of targets (Le Toan et al., 1997; Inoue et al., 2002; Chakraborty et al., 2005; Wang et al., 2009; Kuenzer and Knauer, 2013). Recognizing the role of SAR systems for operational monitoring of rice, international initiatives have been launched including the Asian Rice Crop Estimation and Monitoring (Asia-RiCE) under the Group on Earth Observations Global Agriculture Monitoring (GEOGLAM) framework (Nelson et al., 2014; Oyoshi et al., 2016). Recent studies are also turning their attention towards developing processing chains in cloud-based platforms to evaluate the potential and transferability of operational crop 
characterization at regional scales with the availability of operational SAR systems (Mandal et al., 2018; Singha et al., 2019).

Polarimetric SAR can provide a rich source of data to track temporal dynamics of vegetation conditions (Wiseman et al., 2014; De Bernardis et al., 2015; McNairn and Shang, 2016; Wang et al., 2016; Steele-Dunne et al., 2017; McNairn et al., 2018). In exploiting SAR sensors (ALOS-2, RADARSAT2, and TerraSAR-X), several researchers have reported the potential of crop growth monitoring by relating the associated physical scattering mechanisms from the vegetation canopy to phenology (Lopez-Sanchez et al., 2012, 2014, Torbick et al., 2017; Canisius et al., 2018). Several studies further utilized the dynamics of scattering response for phenology estimation (Lopez-Sanchez et al., 2014; Rossi and Erten, 2014; Vicente-Guijalba et al., 2014; Yuzugullu et al., 2015, 2017; He et al., 2018). Retrieval of biophysical parameters for rice, using backscatter coefficients of different polarizations $(\mathrm{HH}, \mathrm{HV}, \mathrm{VH}$, and VV), has also been demonstrated with acceptable estimation accuracies (Kumar et al., 2013; Yang et al., 2014; Inoue et al., 2014). Several studies have reported on the use of backscatter intensity ratios, the pedestal height, polarization fraction, and polarimetric decomposition parameters as a proxy for crop growth monitoring (Bouvet et al., 2009; Jiao et al., 2011; Blaes et al., 2006; Cable et al., 2014; McNairn and Shang, 2016).

Similar to spectral indices that are well established in optical remote sensing, a vegetation index derived from SAR data could be an alternative, especially for crop growth monitoring during periods of cloud cover. In this direction, Kim and van Zyl (2009) introduced the Radar Vegetation Index (RVI) which uses a measure of scattering randomness within vegeta- 
tion targets. RVI is expected to increase (within the range of 0-1) as volume scattering increases due to development of canopy elements.

A few studies have attempted to utilize the RVI for crop growth monitoring and biophysical parameter estimation (Kim et al., 2012, 2014; Huang et al., 2016). Kim et al. (2012) evaluated the RVI for estimating the Vegetation Water Content (VWC) of rice and soybeans, tracking these crops for the entire growing season using ground-based multi-frequency scatterometers. For both crops, the RVI followed the temporal trend of VWC, with the index increasing up to the heading stage then decreasing until harvest. However, it was observed that the dynamic range of RVI was low (0.35-0.50), in contrast to the significant variation in backscatter intensities during the growth cycle of these crops. Canisius et al. (2018) analyzed the correlation of RVI with the effective Leaf Area Index (LAI) and height of canola and wheat. The RVI showed comparatively a higher sensitivity to the crop height dataset, only when smoothing was performed to suppress the high-frequency noise of temporal RVI.

As an alternative to utilizing the RVI as a proxy for crop condition, scattering models are often used to track plant phenological changes through a growing season. PolSAR scattering models have been utilized in the literature Antropov et al., 2011; Sato et al., 2011; Jagdhuber et al., 2012; Xie et al., 2017) to approximate the scattering behaviour within a resolution cell of SAR observations. The changes in the scattering behaviour with plant phenology could be used as a technique to track crop growth condition (Jiao et al., 2011; Lopez-Sanchez et al., 2014, Canisius et al., 2018). In our recent study, Ratha et al. (2019) proposed a novel radar vegetation 
index which utilizes the generalized volume scattering model (GVSM) for PolSAR data to characterize vegetation growth (Antropov et al., 2011). The generalized volume scattering model based radar vegetation index (GRVI) utilizes the geodesic distance between two Kennaugh matrices projected on unit sphere (Ratha et al., 2017). Unlike the RVI, which models the vegetation layer as an aggregation of randomly oriented dipoles (Kim and van Zyl, 2009), the GRVI offers flexibility to choose the parameters describing the volume scattering component (Antropov et al., 2011). It is important to note that the generalized volume scattering model and the GRVI formulation intrinsically takes into account the elementary scattering components (surface and double bounce) using the co-polarized ratio and the correlation coefficient, respectively.

The GRVI was implemented to characterize wheat and soybeans with a multi-temporal RADARSAT-2 dataset (Ratha et al., 2019). The GRVI trend followed the growth development of both crops, with VWC and Plant Area Index (PAI) increasing as the crops developed. A strong correlation $(>0.76)$ was observed between the GRVI and these growth indicators, for both wheat and soybeans through their vegetative stages. The GRVI outperformed RVI in terms of correlation with these biophysical parameters. This study suggested that for monitoring crop growth using SAR data, it is advantageous to integrate information from a generalized volume scattering model to form a vegetation index. This insight is particularly crucial for rice crop where the scattering power is dominated by both volume and double bounce mechanisms. Unlike other crop types (e.g., canola, soybean, wheat) where the volume scattering is often used as a proxy for canopy development (more 
random scatterers), the scattering mechanism is more complex for rice due to its canopy architecture (vertical stems and erectophile leaf distribution) and the underlying inundated field condition (or saturated soil).

In the research presented here, we utilize the GRVI for monitoring rice growth at different phenological stages. A time-series quad-pol RADARSAT2 dataset over a semi-arid region of India is available for a comparative assessment of GRVI and RVI. This study assesses GRVI for estimating crop biophysical parameter. The rest of the paper is organized as follows: Section 2 briefly describes the study area and the dataset used for the analysis. Section 3 explains in detail the methodology proposed used in this study. Section 4 discusses the results with the main conclusions of this research summarized in Section 5.

\section{Study area and dataset}

This research is conducted over the Joint Experiment for Crop Assessment and Monitoring (JECAM) test site in Vijayawada, India, as shown in Fig. 1. The Vijayawada test site covers the Krishna and Guntur districts in the state of Andhra Pradesh, India. Within this state, roughly $63 \%$ of the geographical area falls in a semi-arid climatic zone (Rao et al., 2013). The test site covers an area of approx. $50 \times 25 \mathrm{~km}^{2}$ and is characterized by three major annual crops-rice, sugarcane, and cotton. These crops are grown in two distinct seasons- monsoon or kharif (June-November) and winter or rabi (DecemberMarch). The flat topography and the dominance of agriculture make this site particularly attractive for SAR based research. A detailed description of the test site is provided in Mandal et al. (2019b). 


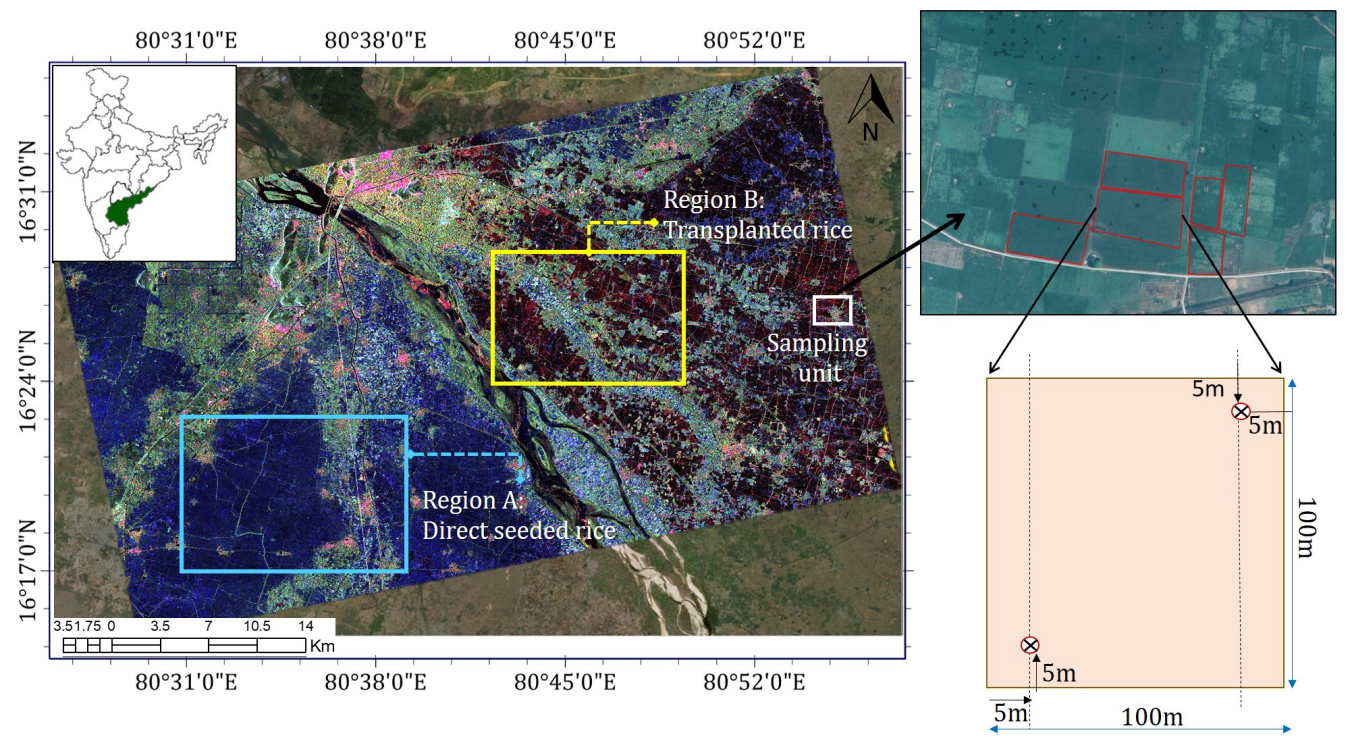

Figure 1: The JECAM-Vijayawada (Andhra Pradesh) India test site with a RADARSAT2 PauliRGB image of 29th July 2018. Two distinct regions for direct seeded rice (Region $\mathrm{A}$ in cyan box) and transplanted rice (Region B in yellow box) are marked with in the test area of $50 \mathrm{~km} \times 25 \mathrm{~km}$. A layout of a sampling unit (white box) is highlighted at the right.

The research presented in this manuscript focuses on rice cultivation during the kharif season, within the JECAM test site. In particular, two major rice cultivation techniques, i.e., transplanted rice (TR) and direct seeded rice (DSR) are being practiced (NIBIO, 2012, APAgriculture, 2018). In traditional farming, rice is primarily grown by transplanting seedlings into flooded puddled fields. The TR cultivation requires large volumes of water (approx. $150 \mathrm{~cm}$ of total irrigation water) for puddling and further maintenance of standing-water conditions (Singh et al., 2001). Alternatively, the DSR cultivation is being promoted in this region (Fig. 1), which includes alternate wetting and drying instead of a persistent standing-water condition (Mahajan et al., 2013). The DSR method of cultivation reduces water 
consumption by approximately $30 \%$ by eliminating the nursery raising, puddling, transplanting, and initial standing-water condition during the early tillering stage (Balasubramanian and Hill, 2002; Cabangon et al., 2002).

\subsection{In-situ sampling strategy}

Field campaigns were conducted in the kharif season to track different rice growth stages from June to November 2018. During the campaign, in-situ measurements were collected of crops and soil for 75 agricultural fields. The nominal size of each field is around $100 \mathrm{~m} \times 100 \mathrm{~m}$. In each sampling field, soil moisture was measured at two sampling locations, arranged in two parallel transects along the row direction, as shown in Fig. 1. Each transect was separated by approximately $80 \mathrm{~m}$. Soil moisture was measured at each point using a theta-probe. However, it is important to note that soil underlying the rice canopy was saturated during most of the growing season due to frequent irrigation and rainfall events.

In each field, vegetation sampling was conducted at two points (Fig. 1) corresponding to the soil sampling locations. Vegetation sampling included the measurement of PAI, plant height, density, and phenology through nondestructive approaches. The PAI was estimated from photographs using the concept of hemispherical digital photography (Jonckheere et al., 2004; Weiss et al., 2004). During each of the measurement day, ten photos were taken along two transects which are separated by $2 \mathrm{~m}$ in each sampling point, using a wide-angle lens mounted on a digital camera. These photos record the geometry of the plant canopy obstructing the field of view against the soil surface. All images were post-processed using the CanEYE software (INRA, 2017) to provide an estimate of PAI. The phenological growth of rice is usually ex- 

in quad-pol mode with a scene center incidence angle of $35.2^{\circ}$.

Table 1: Specification of C-band quad-pol RADARSAT-2 acquisitions over the test site during the field campaign

\begin{tabular}{lcccc}
\hline Acquisition date & Beam mode & $\begin{array}{c}\text { Incidence angle } \\
\text { range }(. \mathrm{deg})\end{array}$ & Orbit & $\begin{array}{c}\text { In-situ } \\
\text { measurements }\end{array}$ \\
\hline $05-07-2018$ & FQ15W & $33.7-36.7$ & Ascending & 04 Jul., 05 Jul. \\
29-07-2018 & FQ15W & $33.7-36.7$ & Ascending & 01 Aug., 02 Aug. \\
22-08-2018 & FQ15W & $33.7-36.7$ & Ascending & 22 Aug., 23 Aug. \\
15-09-2018 & FQ15W & $33.7-36.7$ & Ascending & 14 Sep., 15 Sep. \\
$09-10-2018$ & FQ15W & $33.7-36.7$ & Ascending & 08 Oct., 09 Oct. \\
02-11-2018 & FQ15W & $33.7-36.7$ & Ascending & 02 Nov., 03 Nov. \\
$26-11-2018$ & FQ15W & $33.7-36.7$ & Ascending & 25 Nov., 26 Nov. \\
\hline
\end{tabular}

pressed with three major stages: vegetative, reproductive, and maturation or ripening. Each of these stages has particular morphological changes and variations in the biophysical parameters. These phenological developments were indicated in terms of a quantitative measure using the $\mathrm{BBCH}$ (Biologische Bundesanstalt Bundessortenamt und CHemische Industrie) scale by visual inspection (Bleiholder et al., 2001). The detailed description of vegetation and soil sampling strategies can be found in the field campaign report (Mandal et al. 2019b).

\subsection{SAR dataset}

During the campaign, seven RADARSAT-2 images were acquired in Fine Wide quad-pol mode (FQW) as given in Table1. The selection of acquisition dates was based on in-situ measurement periods. All these acquisitions were 


\subsection{GRVI Formulation}

In PolSAR theory, the Radar Vegetation Index (RVI) proposed by Kim and van Zyl (2009) uses the eigenvalue spectrum obtained from the coherency $\boldsymbol{T}$ matrix (van Zyl, 2011). It is expressed as (1):

$$
R V I=\frac{4 \min \left(\lambda_{1}, \lambda_{2}, \lambda_{3}\right)}{\lambda_{1}+\lambda_{2}+\lambda_{3}}
$$

where $\lambda_{i}$ denotes the $i$-th eigenvalue of $\boldsymbol{T}, i=1,2,3$.

In PolSAR scattering theory, the $4 \times 4$ real Kennaugh matrix $\boldsymbol{K}$ for incoherent targets is expressed in terms of the elements of the coherency matrix $\boldsymbol{T}$ as,

$$
\boldsymbol{K}=\left[\begin{array}{cccc}
\frac{T_{11}+T_{22}+T_{33}}{2} & \Re\left(T_{12}\right) & \Re\left(T_{13}\right) & \Im\left(T_{23}\right) \\
\Re\left(T_{12}\right) & \frac{T_{11}+T_{22}-T_{33}}{2} & \Re\left(T_{23}\right) & \Im\left(T_{13}\right) \\
\Re\left(T_{13}\right) & \Re\left(T_{23}\right) & \frac{T_{11}-T_{22}+T_{33}}{2} & -\Im\left(T_{12}\right) \\
\Im\left(T_{23}\right) & \Im\left(T_{13}\right) & -\Im\left(T_{12}\right) & \frac{-T_{11}+T_{22}+T_{33}}{2}
\end{array}\right]
$$

where $\Re$ and $\Im$ denote the real and imaginary part of a complex number.

The GRVI proposed in Ratha et al. (2019) uses a similarity measure between the observed $\boldsymbol{K}$ and the Kennaugh matrix, $\boldsymbol{K}_{\mathrm{v}}$ associated with the generalized volume scattering model (Antropov et al., 2011), which is used 
as a reference model for the scattering from vegetation (3):

$$
\boldsymbol{K}_{\mathrm{v}}=\frac{1}{\frac{3(1+\gamma)}{4}-\frac{\sqrt{\gamma}}{6}}\left[\begin{array}{cccc}
\frac{3}{2}(1+\gamma)-\frac{\sqrt{\gamma}}{3} & \gamma-1 & 0 & 0 \\
\gamma-1 & \frac{1}{2}(1+\gamma)+\frac{\sqrt{\gamma}}{3} & 0 & 0 \\
0 & 0 & \frac{1}{2}(1+\gamma)+\frac{\sqrt{\gamma}}{3} & 0 \\
0 & 0 & 0 & \frac{1}{2}(1+\gamma)-\sqrt{\gamma}
\end{array}\right]
$$

The GVSM proposed in Antropov et al. (2011) is represented by two parameters: $\gamma$ and $\rho$, which correspond to the co-polarized ratio and the correlation coefficient (fixed at $\rho=1 / 3$ ), respectively. The similarity measure is derived from the geodesic distance (Ratha et al., 2018) between observed $\boldsymbol{K}$ and a reference Kennaugh matrix $\boldsymbol{K}_{i}$ :

$$
f_{i}=1-\mathrm{GD}\left(\boldsymbol{K}, \boldsymbol{K}_{i}\right)
$$

where GD denotes the geodesic distance between two Kennaugh matrices $\boldsymbol{K}_{1}$ and $\boldsymbol{K}_{2}$ on the unit sphere. It is defined as:

$$
\operatorname{GD}\left(\boldsymbol{K}_{1}, \boldsymbol{K}_{2}\right)=\frac{2}{\pi} \cos ^{-1} \frac{\operatorname{Tr}\left(\boldsymbol{K}_{1}^{T} \boldsymbol{K}_{2}\right)}{\sqrt{\operatorname{Tr}\left(\boldsymbol{K}_{1}^{T} \boldsymbol{K}_{1}\right)} \sqrt{\operatorname{Tr}\left(\boldsymbol{K}_{2}^{T} \boldsymbol{K}_{2}\right)}}
$$

where $\operatorname{Tr}$ denotes the trace of a matrix and the superscript $T$ denotes the matrix transpose. The $2 / \pi$ factor is used to normalize its range to $[0,1]$.

In the formulation of GRVI (6), the similarity measure, $f_{\mathrm{v}}(7)$ between the generalized volume scattering model $\boldsymbol{K}_{\mathrm{v}}$ and the observed Kennaugh matrix $\boldsymbol{K}$ is obtained using the geodesic distance $\mathrm{GD}_{\mathrm{v}}=\operatorname{GD}\left(\boldsymbol{K}, \boldsymbol{K}_{\mathrm{v}}\right)$. A modulating parameter $\beta$ is introduced in $(7)$ which is the ratio of minimum to maximum geodesic distances between $\boldsymbol{K}$ and elementary targets: trihedral 


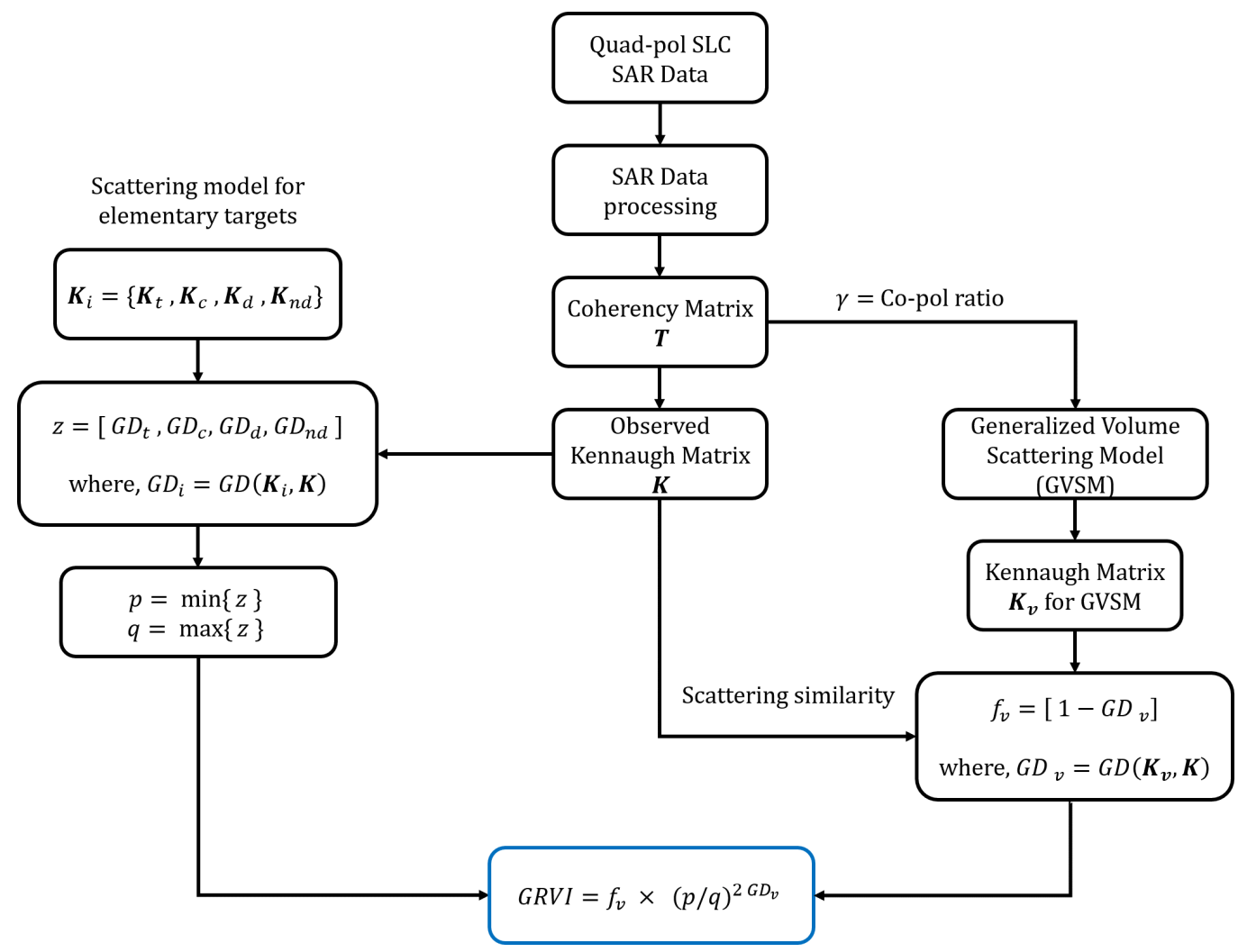

Figure 2: Schematic workflow for the Generalized volume scattering model based Radar Vegetation Index (GRVI) formulation.

$\left(\boldsymbol{K}_{\mathrm{t}}\right)$, cylinder $\left(\boldsymbol{K}_{\mathrm{c}}\right)$, dihedral $\left(\boldsymbol{K}_{\mathrm{d}}\right)$, and narrow dihedral $\left(\boldsymbol{K}_{\mathrm{nd}}\right)$ as given in (8). The Kennaugh matrix forms of these elementary targets are shown 
in Ratha et al. (2019).

$$
\begin{gathered}
\text { GRVI }=\beta f_{\mathrm{v}}, \quad 0 \leq \mathrm{GRVI} \leq 1, \\
f_{\mathrm{v}}=\left(1-\mathrm{GD}_{\mathrm{v}}\right), \quad \beta=\left(\frac{p}{q}\right)^{2 \mathrm{GDv}}, \\
p=\min \left[\begin{array}{c}
\mathrm{GD}\left(\boldsymbol{K}, \boldsymbol{K}_{\mathrm{t}}\right) \\
\mathrm{GD}\left(\boldsymbol{K}, \boldsymbol{K}_{\mathrm{c}}\right) \\
\operatorname{GD}\left(\boldsymbol{K}, \boldsymbol{K}_{\mathrm{d}}\right) \\
\operatorname{GD}\left(\boldsymbol{K}, \boldsymbol{K}_{\mathrm{nd}}\right)
\end{array}\right], q=\max \left[\begin{array}{c}
\mathrm{GD}\left(\boldsymbol{K}, \boldsymbol{K}_{\mathrm{t}}\right) \\
\mathrm{GD}\left(\boldsymbol{K}, \boldsymbol{K}_{\mathrm{c}}\right) \\
\mathrm{GD}\left(\boldsymbol{K}, \boldsymbol{K}_{\mathrm{d}}\right) \\
\operatorname{GD}\left(\boldsymbol{K}, \boldsymbol{K}_{\mathrm{nd}}\right)
\end{array}\right]
\end{gathered}
$$

The two extreme cases of GRVI viz., GRVI $=0$ and GRVI $=1$ correspond to $\boldsymbol{K} \in\left\{\boldsymbol{K}_{\mathrm{t}}, \boldsymbol{K}_{\mathrm{c}}, \boldsymbol{K}_{\mathrm{d}}, \boldsymbol{K}_{\text {nd }}\right\}$ and $\boldsymbol{K}=\boldsymbol{K}_{\mathrm{v}}$, respectively. A schematic workflow of the GRVI is provided in Fig. 2 .

\subsection{Preprocessing of $S A R$ data}

In this study, seven RADARSAT-2 images (Table 1) were acquired in SLC format. The RADARSAT-2 SLC product in FQ15W beam mode has range and azimuth pixel spacing of $4.73 \mathrm{~m}$ and $5.11 \mathrm{~m}$, which correspond to a nominal resolution equal to $5.2 \mathrm{~m}$ and $7.6 \mathrm{~m}$ in ground-range and azimuth directions, respectively (Slade, 2018). The full-polarimetric images are multilooked by $2 \times 2$ (in the range and azimuth) to generate the coherency matrix $\boldsymbol{T}$, with the spatial resolution of $10.4 \mathrm{~m}$ and $15.2 \mathrm{~m}$. The elements of the $\boldsymbol{T}$ matrix are then used to calculate the Kennaugh matrix $\boldsymbol{K}$ as discussed in Sec. 3.1. The GRVI images are generated from the derived $\boldsymbol{K}$ for each acquisition over a $7 \times 7$ moving overlapping window. The GRVI images are then co-registered using ground control points (GCP) with an RMSE $\leq 0.54 \mathrm{~m}$ 
and geocoded with an output pixel size of $10 \mathrm{~m}$ and $10 \mathrm{~m}$ on the ground. A comparative analysis is performed for the full crop season between GRVI and RVI. The RVI obtained from the $\boldsymbol{T}$ matrix over a $7 \times 7$ moving overlapping window is co-registered using GCPs with an RMSE of approx. $0.53 \mathrm{~m}$. The GRVI and RVI values for each sampling location (point measurements) are extracted over a $3 \times 3$ window.

\section{Results and discussion}

The vegetation indices (both the GRVI and RVI) for different sampling sites are generated from the RADARSAT-2 quad-pol data set, and the temporal analysis is performed at different growth stages for TR and DSR. Figs. 3 and 10 plot the temporal trends of GRVI and RVI, averaged for the two sampling points in each plot. Furthermore, the correlation of radar vegetation indices with PAI $\left(\mathrm{m}^{2} \mathrm{~m}^{-2}\right)$ is analyzed for each rice type. In total, 102 samples from 20 TR fields and 200 samples from 41 DSR fields are used for the correlation analysis (Fig. 8 and 12). The significance tests are performed along with the correlation analysis. Linear regression models are also developed for PAI estimation, with independent training and validation datasets using these vegetation indices.

\subsection{Transplanted rice (TR)}

The temporal responses of GRVI over the phenological stages of transplanted rice fields are shown in Fig. 3. From the TR fields, 8 representative fields (field numbers: 024, 044, 063, 141, 151, 153, 174, 113) distributed throughout the region are used for the temporal analysis. These analyses are also supported with in-situ measurements of PAI. A primary qualitative 

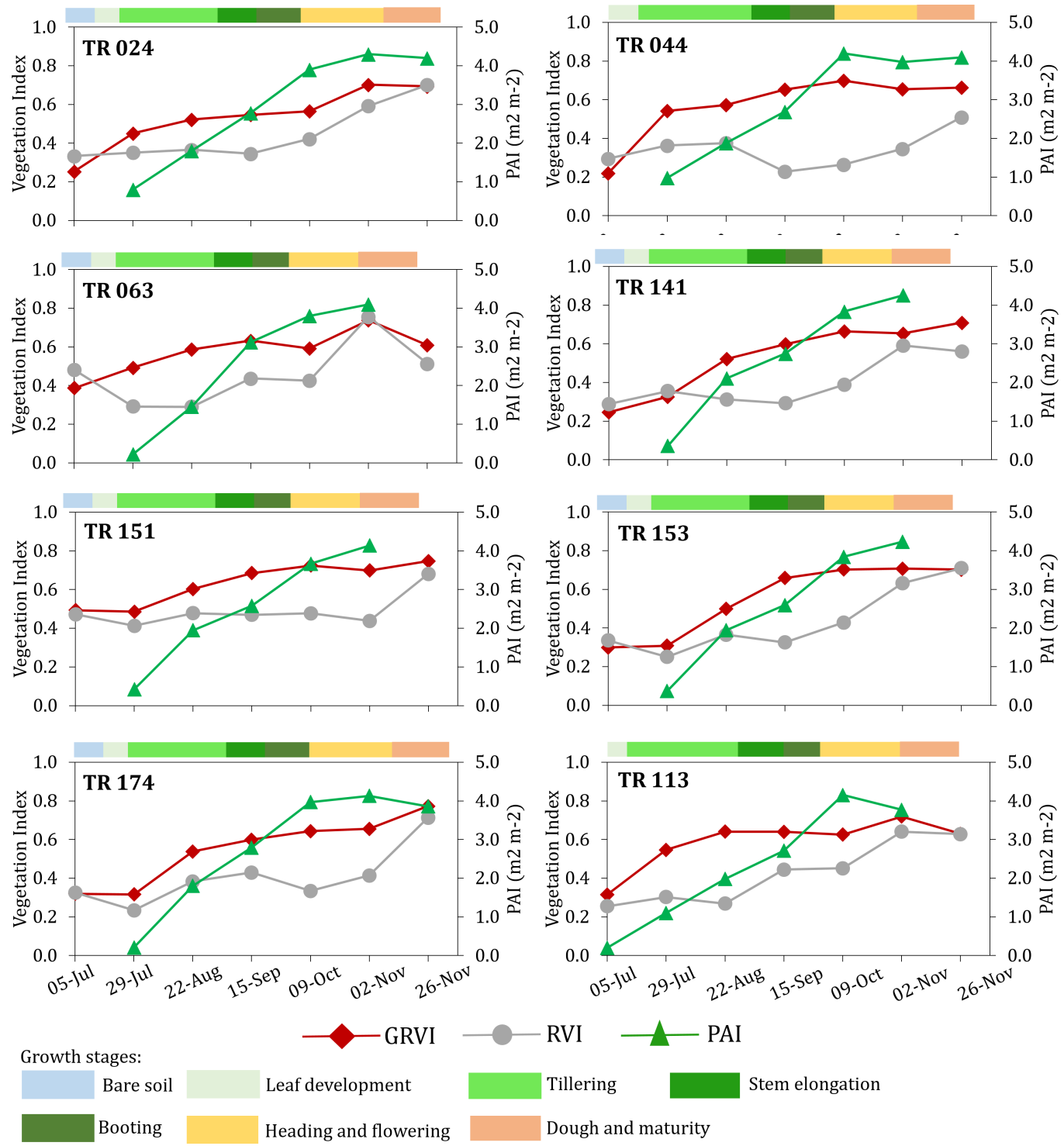

Figure 3: Temporal pattern of GRVI and RVI for transplanted rice (TR) fields at different growth stages. The in-situ measurements of Plant Area Index (PAI, $\left.\mathrm{m}^{2} \mathrm{~m}^{-2}\right)$ are plotted on the secondary axis for each field.

analysis indicates that the growth trends of rice are similar irrespective of

field numbers; PAI increases as the rice crop develops. 

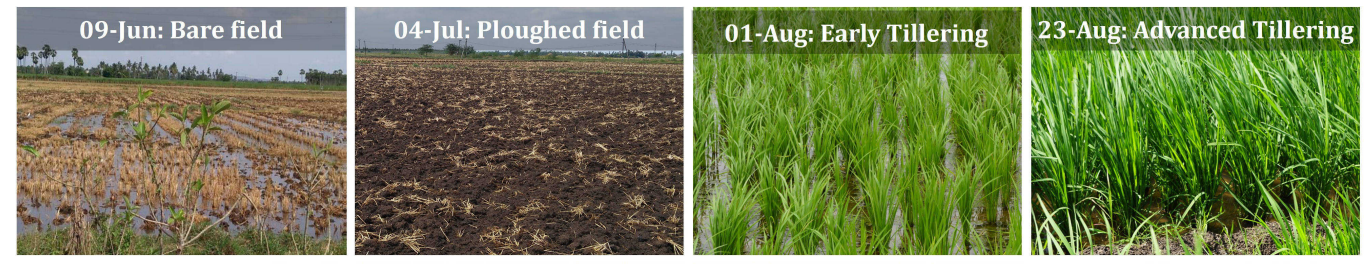

15-Sep: Booting
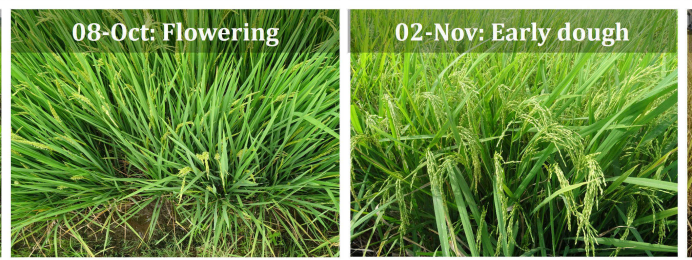

25-Nov: Maturity

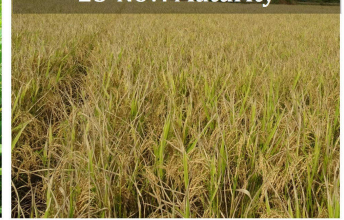

Figure 4: Field conditions of a transplanted rice (TR) during the campaign.

At the field preparation stage (on 05 July), although the plant development has not yet started (Fig. 4), both the GRVI and RVI values are high (within a range of $0.25-0.35$ ). Theoretically, for the bare field condition (similar to a trihedral type scattering) the GRVI lies close to zero (Ratha et al., 2019). However, the relatively high values of the indices are likely due to soil roughness as compared to the $5.6 \mathrm{~cm}$ C-band wavelength. The in-situ measurements confirmed that the soil roughness was high due to the tillage operations.

With crop establishment completed by 29 July, the GRVI values start to increase monotonically. At the early tillering stage (29 July), the magnitude of GRVI is $\lesssim 0.4$ for the majority of the plots. However, for TR044 and TR113, a sharp increase in GRVI (up to 0.57) is observed on 29 July. This increase may be due to development of more number of tillers as these fields were more advanced with an active tillering stage with $\mathrm{PAI} \sim 1.0 \mathrm{~m}^{2} \mathrm{~m}^{-2}$. The GRVI continues to increase on 22 August when the majority of rice fields are in their active to the end of the tillering stage. These high GRVI 
values may be due to the high degree of randomness in scattering from the canopy elements during the tillering stages. Also, the underlying water may contribute to both the volume and even-bounce scattering components.

The GRVI values reached a maximum (approx. 0.75) when the crop advanced to its heading and flowering stages on 09 October. The in-situ measurements reported PAI of up to approximately $4.2 \mathrm{~m}^{2} \mathrm{~m}^{-2}$. This increase in the GRVI values indicates the dominance of volume scattering in the fields which might increase the similarity between the observed $\boldsymbol{K}$ and the $\boldsymbol{K}_{v}$ of the GVSM. However, changes in GRVI values after the heading stage are not apparent. During the dough and maturity stages, the GRVI values are still high, which may be a function of volume scattering from the upper canopy elements of rice. During the heading to maturity stages of rice with ears emerging, multiple scattering dominates within the total backscattered power in C-band (Kumar and Rao, 2015). Similar observations with volume scattering power for the temporal response of rice are reported in Li et al. (2012). The volume scattering power derived from the Freeman-Durden decomposition applied to RADARSAT-2 is stable from the heading to maturity stage of rice. The high entropy values $(\mathrm{H} \sim 0.8)$ and an average scattering type $\alpha$ of approximately $50^{\circ}$ is also in accordance with these observations during these growth stages (Li et al., 2012).

Another important aspect for rice monitoring is the lodging effect, which is pronounced during the reproductive to maturity stage. Lodging effects are often due to heavy grains load, loosening stem strength, and high wind. Representative fields in this category where lodging was observed are TR141 and DSR205 in November. The GRVI values in the temporal plots also 


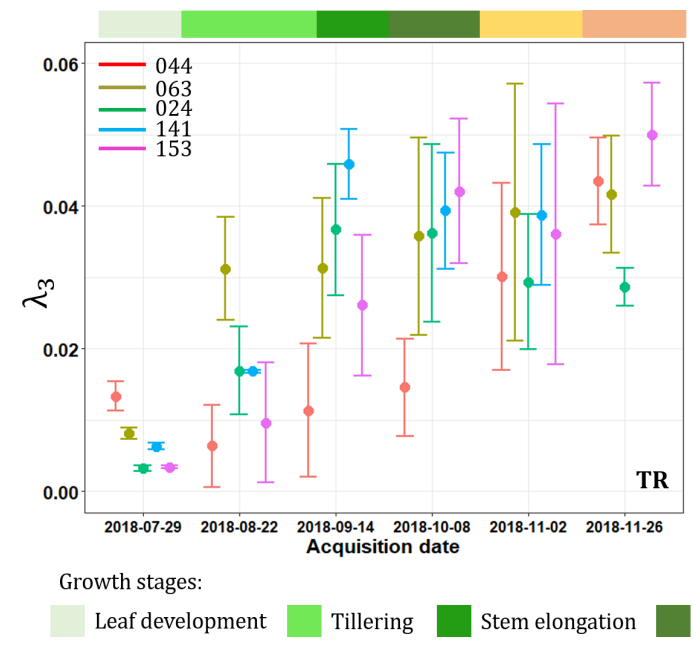
stage (09 Oct).

indicate this effect with comparatively lower values than the high vegetative

Figure 5: Temporal pattern of third eigenvalue $\left(\lambda_{3}\right)$ derived from coherency matrix $(\boldsymbol{T})$ for transplanted rice (TR) and direct seeded rice (DSR) fields at different growth stages.

The increase in RVI values is less apparent during the vegetative stage of the rice crop, as compared to GRVI. The dynamic range of RVI through the rice growth period is also lower when compared with the range associated with GRVI. An issue to consider with RVI is its formulation from the eigenvalue spectrum. The numerator in (11) i.e., third eigenvalue, $\lambda_{3}$ is more affected by noise rather than changes with vegetation randomness. It is also apparent from Fig. 5 that the standard deviation of $\lambda_{3}$ increases as the rice crop advances from the early tillering stage (22 August) to dough and maturity, although its mean value increases with PAI and plant growth. The structural heterogeneity of plants during the reproductive to maturity stage might lead to a spatial variance within a plot (Yuzugullu et al., 2018). $\mathrm{He}$ et al. (2018) also reported similar heterogeneity in the backscatter signal, 
which was influenced by the planting density of rice.

Compared to radar vegetation indices, the variations in the backscatter intensities in different polarization channels are apparent during different growth stages. In order to check the consistency of C-band measurements for the current acquisitions, we evaluated the backscatter intensities in co(HH, VV) and cross-pol (HV) channels, as shown in Fig. 6 and 11. These investigations exclusively on the temporal trends of backscatter intensities with plant growth are not new. However, they constitute the principal of most of the experiments carried out in the literature for rice mapping and monitoring with radar data.

For transplanted rice, it is observed that the backscatter intensity in copol channels (HH and VV) are very low on 29 July in majority of the fields, as shown in Fig. 6. It is likely due to low vegetation growth during the early leaf development stage and the underlying inundated field condition. The backscatter powers increased during the tillering and stem elongation stage. The double-bounce scattering mechanism becomes stronger due to the interaction between the rice stems and the underlying water surface. This means a lower backscatter power in the VV polarization channel because of its stronger attenuation than $\mathrm{HH}$ resulting from the vertical rice plants. This difference between the co-pol channels was reported by their ratio in (Lopez-Sanchez et al., 2014). Concerning the cross-pol response, it indicated lower value than the co-pol channels, but also exhibits a high growth as plants canopy develops. From the heading stage onward, the variation of the backscattering intensities is less pronounced than the previous phenological stages. The backscatter responses slowly decrease for both po- 

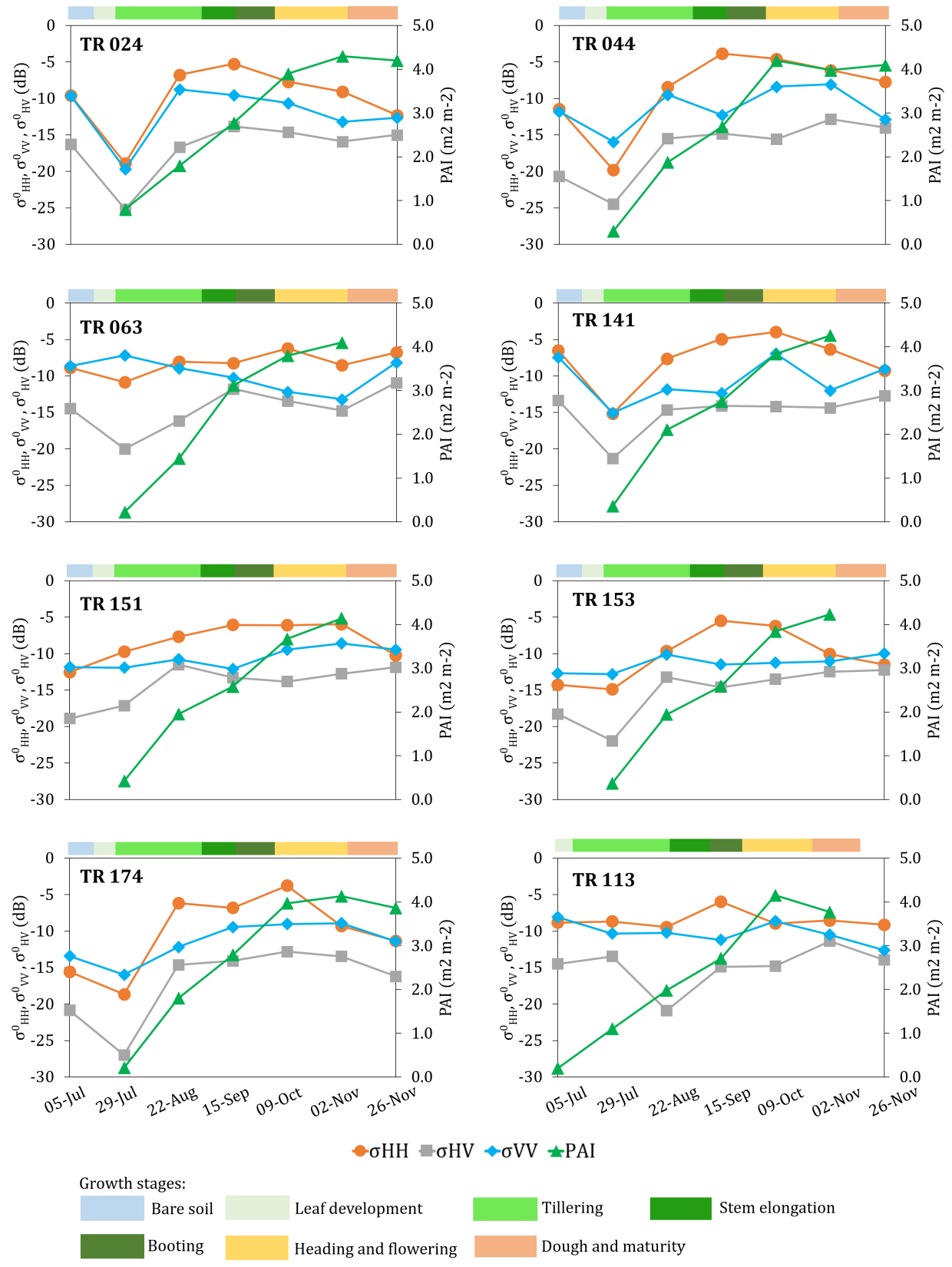

$\diamond \sigma \mathrm{VV} \neq \mathrm{PAI}$ 


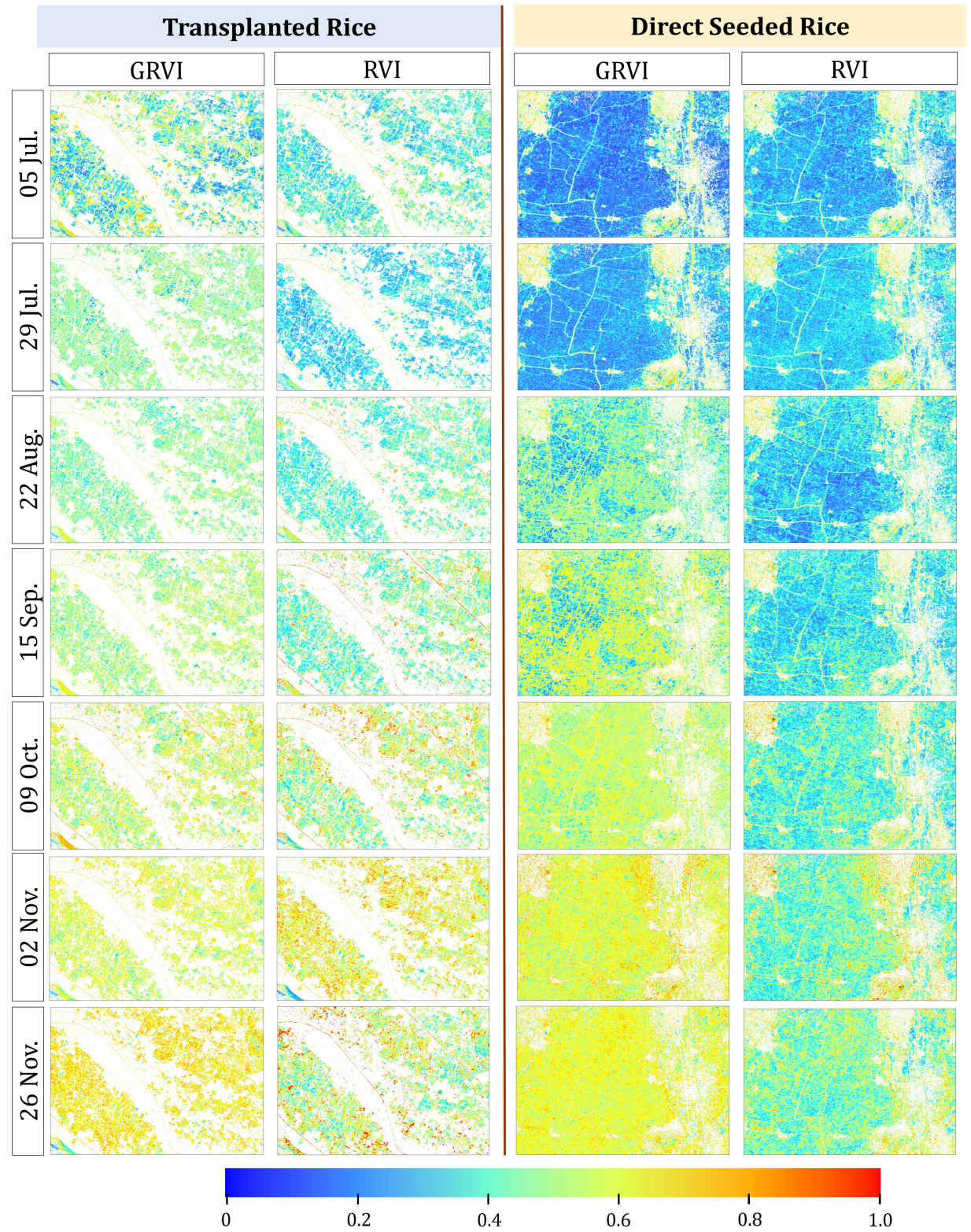

Figure 7: GRVI and RVI maps over the test site for seven acquisitions (05 Jul., 29 Jul., 22 Aug., 15 Sep., 09 Oct., 02 Nov., and 26 Nov.) of RADARSAT-2. Two subsets (Region A and Region B, in Fig. 1) are highlighted for the direct seeded rice and transplanted rice. 
larizations during the maturity stage as the rice plants gradually wither and water content decreases. The temporal trends at different polarization channels plotted in Fig. 4 agree with the well-known response from rice fields at C-band radar systems, which are reported in literature (Le Toan et al., 1997; Inoue et al., 2002; Bouvet et al., 2009; Lopez-Sanchez et al., 2011, 2014).
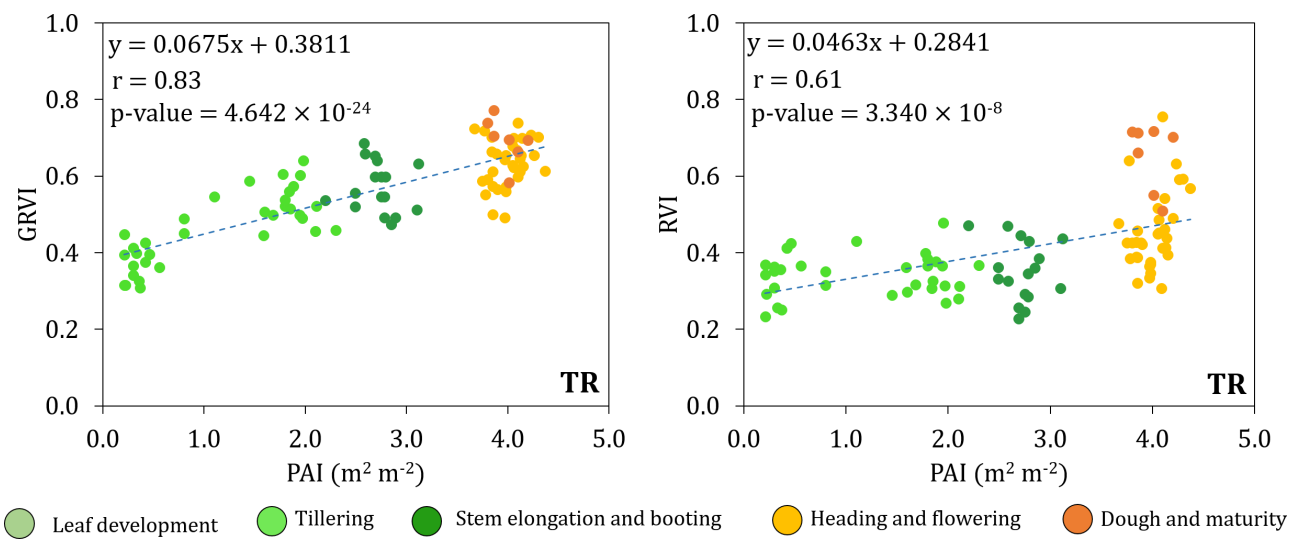

Figure 8: Correlations (r) between vegetation indices (GRVI and RVI) and plant area index $\left(\mathrm{PAI}, \mathrm{m}^{2} \mathrm{~m}^{-2}\right)$ for transplanted rice (TR). Samples from several phenological stages are highlighted by different colours.

The GRVI maps for the seven acquisition dates are shown in Fig. 7 over a subset of the test site (Region-B in Fig. 1). Both spatial and temporal variability is observed in these maps, which are similar to the temporal behavior of transplanted rice, as shown in Fig. 3. The qualitative comparison between RVI and GRVI maps for the seven acquisition dates (Fig. 7 over a subset of the test site Region-B) confirms the superior performance of GRVI. The correlation analysis of GRVI and RVI with PAI is shown in Fig. 8 for different phenological stages of transplanted rice. The correlation coefficient $(r)$ of GRVI with PAI is 0.83 , higher than that of RVI $(r=0.61)$. In particular, GRVI outperforms RVI for the period from tillering to booting with stronger 
correlation, as lower variance associated with GRVI. As the transplanted rice starts heading and moves to maturity, a higher variance is observed for RVI. As previously stated, this higher variance may be due to the noisy values associated with $\lambda_{3}$. Variations in the vegetation indices during later growth stages may be explained by scattering from the upper canopy layer along with the saturation of PAI.

\subsection{Direct Seeded Rice (DSR)}

Direct seeding of the rice crop is gaining importance in the semi-arid regions of India. Differences in extent, timing, and duration of standing water in DSR plots, as compared to that of conventional TR cultivated plots, will impact SAR scattering characteristics. DSR cultivation begins with the preparation of a smooth seedbed for direct sowing, in order to promote proper seed establishment (Fig. 9). The temporal response of GRVI over the phenological stages of DSR fields are shown in Fig. 10. Amongst several DSR fields, 8 representative fields (field numbers: 205, 212, 242, 253, 271, 285, 263 and 303), distributed throughout the region, are presented. The response of GRVI is compared to that of RVI, with in-situ measured PAI aiding in the interpretation of these results. As with the TR cultivation, the growth trends of DSR plots are similar irrespective of the field numbers; an increase of PAI with crop development.

It is apparent from Fig. 10 that GRVI increases monotonically as crop establishment is completed by 22 August. Here, it is important to note that crop development to tillering is delayed in DSR (up to 15 September) as compared to TR. Unlike seedling transplanted from the nursery-bed to main plots flooded with water in TR cultivation, for DSR plants emerge 

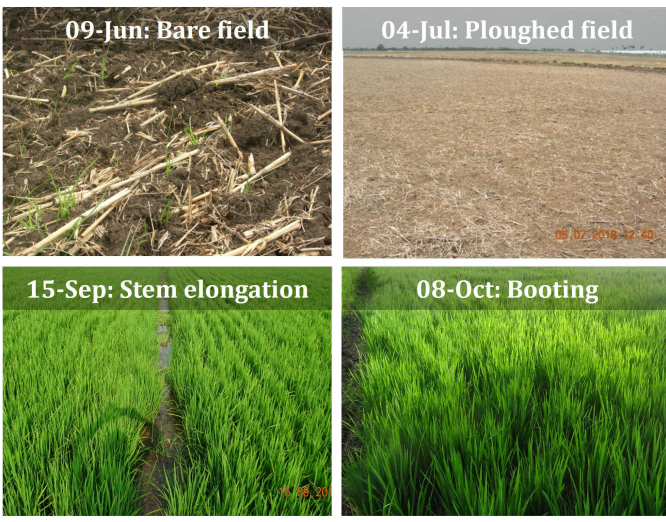

08-0ct: Booting

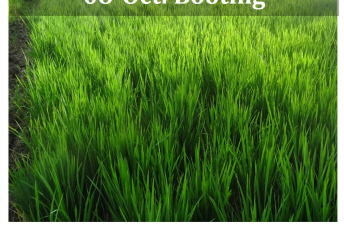

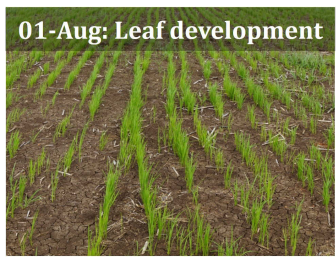

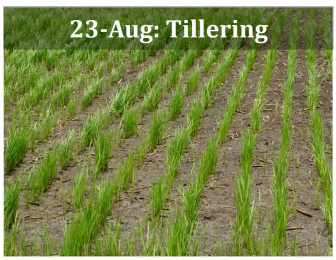

25-Nov: Dough stage
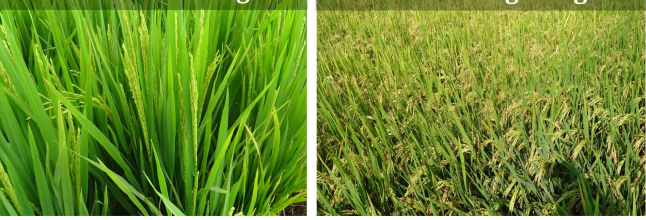

Figure 9: Field conditions of a direct seeded rice (DSR) during the campaign.

directly from the sown seeds in the main plot. Hence, crop establishment and accumulation of peak PAI are generally delayed. This delay is apparent in the temporal PAI plots shown in Fig. 10.

At the early tillering stage (on 22 August) the magnitude of GRVI is $<0.4$ for the majority of the plots. GRVI continues to increase during the vegetative stage and ends at booting around 09 October. GRVI values reach a maximum (approx. 0.62-0.75) at heading and flowering stages on 02 November. The in-situ measurements of PAI during this period confirm an increase in PAI to approximately $4.3 \mathrm{~m}^{2} \mathrm{~m}^{-2}$. However, changes in GRVI values after the heading stage are not apparent (02 November). Also, during the dough and maturity stages, both the GRVI and RVI values are inconsistent among different fields. The GRVI maps over a subset of the test site (Region-A in Fig. 1) also qualitatively confirm variability both in spatial and temporal scale (Fig. 7). Moreover, the changes indicated by GRVI are more apparent in the DSR region than the TR area, which may be due to complex scattering phenomena in TR fields given the presence of standing water. 

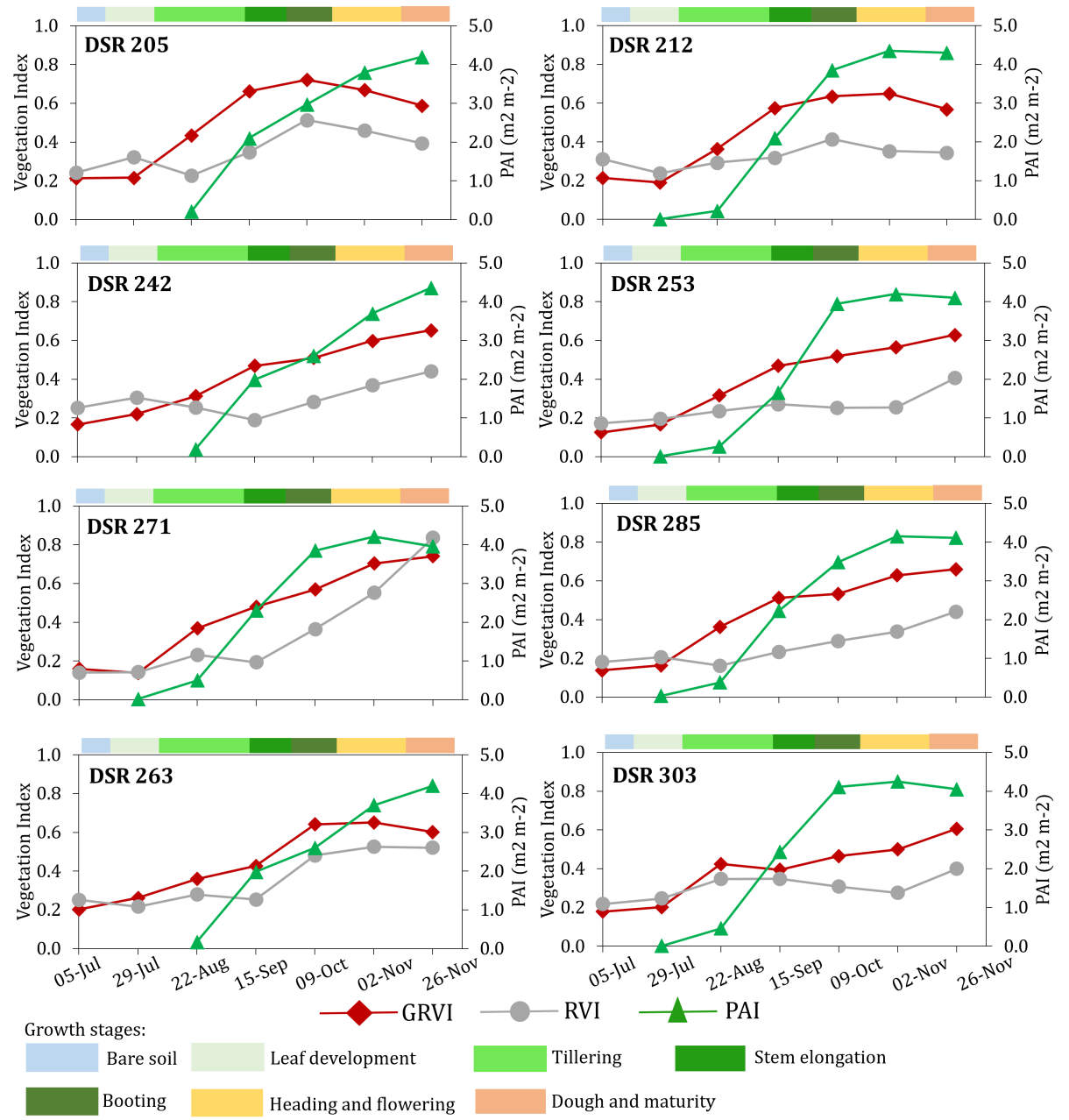

Tillering $\quad$ PAI
Dough and maturity

Figure 10: Temporal pattern of GRVI and RVI for direct seeded rice (DSR) fields at different growth stages. The in-situ measurements of PAI, $\mathrm{m}^{2} \mathrm{~m}^{-2}$ are plotted in secondary axis for each field.

Similar to the TR backscatter signal, the DSR plots also indicate backscatter intensity variations with phenological stages (Fig. 11). However, during the early leaf development stage, the backscatter powers are notably higher than the majority of TR fields. It is likely due to the delayed plant development up to tillering stage. The in-situ measurements also confirm a 
delayed accumulation of peak PAI for DSR fields. This delay is apparent in the temporal PAI and backscatter intensity plots shown in Fig. 11.
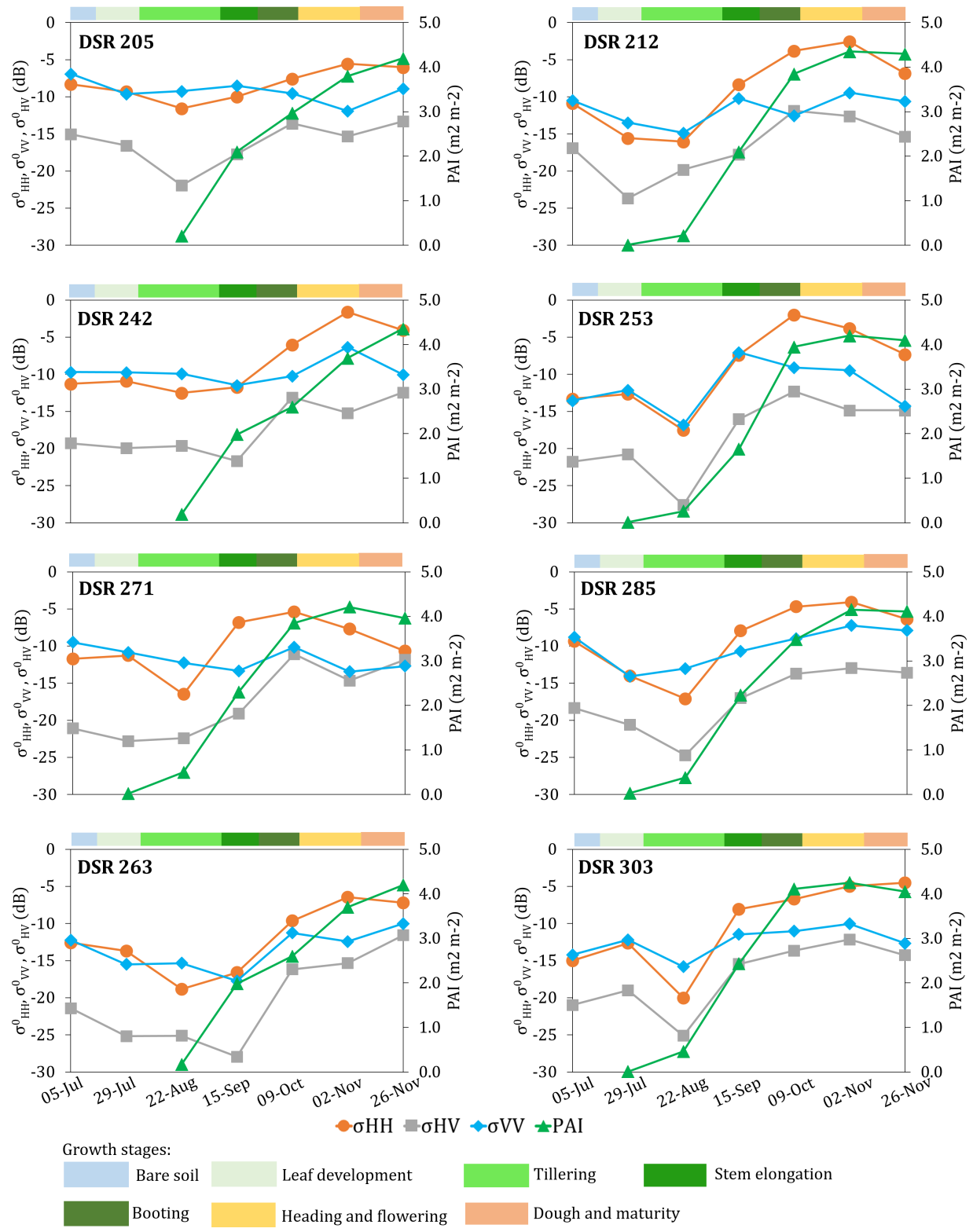

Figure 11: Temporal pattern of backscatter intensities in the HH, VV, and HV channels for direct seeded rice (DSR) fields at different growth stages. The in-situ measurements of Plant Area Index (PAI, $\mathrm{m}^{2} \mathrm{~m}^{-2}$ ) are plotted on the secondary axis for each field. 

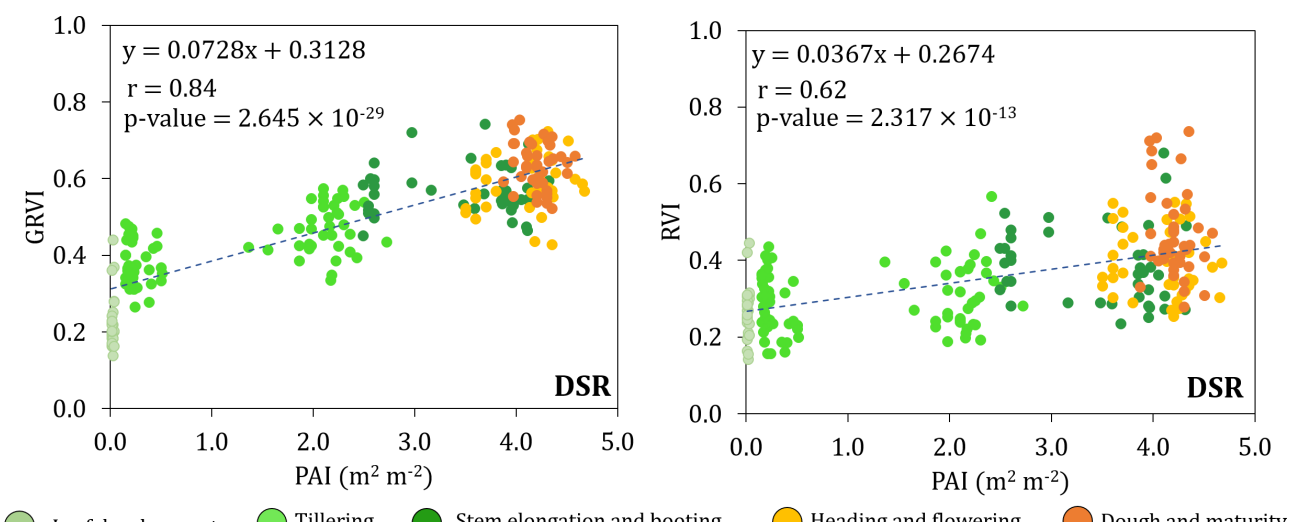

Leaf development

Figure 12: Correlations (r) between vegetation indices (GRVI and RVI) with plant area index $\left(\mathrm{PAI}, \mathrm{m}^{2} \mathrm{~m}^{-2}\right.$ ) for direct seeded rice (DSR). Samples from several phenological stages are highlighted in different colours.

Increases in RVI throughout the phenological stages of rice development are different when compared to GRVI. The dynamic range of RVI is lower relative to GRVI, throughout the entire growing period. As well, the correlation analysis of GRVI shows its competence with RVI as given in Fig. 12 . The correlation coefficient $(r)$ of GRVI with PAI is 0.84 , significantly higher than the correlation between RVI and PAI $(r=0.62)$. The GRVI of DSR fields is more sensitive to the changes in PAI, relative to RVI, as was also observed with the responses from the TR fields. This improved sensitivity was particularly noted for the tillering to booting stages. As the DSR crop advanced from the heading to maturity stages, the responses associated with RVI had higher variance. This increased variance is likely due to the nature of $\lambda_{3}$, as shown in Fig. 5. It is worth mentioning that in addition to volume scattering, the double bounce scattering mechanism is also one of the major contributors to the total backscatter power given the erectophile geometry of rice crops. This characteristic may lead to low signal to noise ratio (SNR) 
for the third eigenvalue. On the other hand, the GRVI suitably takes into account the GVSM parameters along with the modulation parameter $\beta$ (7) to better capture changes in the crop morphology.

\subsection{Potential of $T R$ and $D S R$ discrimination}

In addition to the temporal dynamics of vegetation indices, it is also interesting to evaluate the characterization capability of VIs for both rice types. The literature reports that techniques to characterize rice growth depend primarily on the detection of the backscattered signal from the underlying water at the start of the growing season (Le Toan et al., 1997; Nelson et al., 2014; Mandal et al. 2018). These techniques are typical of transplanted rice (TR) cultivation. In contrast, the DSR cultivation includes alternate wetting and drying of the soil, without extended periods of standing water. This difference in the cultivation practice is challenging to characterize with SAR backscatter coefficients (Fikriyah et al., 2019).

In principle, it would be possible to characterize differences between cultivation practices early in the rice growing season. Even though limited investigations have focused on the discrimination of rice cultivation practices using SAR, it is imperative to focus on the period of land preparation to the tillering and stem elongation stages (Choudhury and Chakraborty, 2006, Yang et al., 2017; Phan et al., 2018).

A recent study by Fikriyah et al. (2019), using C-band dual-pol Sentinel-1 backscatter intensities, demonstrated that TR and DSR cultivation practices could be discriminated. In our experiment, even though the correlation of PAI with vegetation indices for TR is similar to that of DSR, the sensitivity of GRVI to PAI varies among phonological stages as shown in Fig. 3 and 10 . The 
spatio-temporal maps (Fig. 7) also highlight variations between TR and DSR regions at early growing to late vegetative stages. However, the vegetation indices appeared similar for TR and DSR fields during heading to maturity stages. Nevertheless, the discrimination capability of GRVI is superior to that of RVI for qualitative assessment of rice cultivation practices.

\subsection{PAI estimation from vegetation indices}

The retrieval of PAI from PolSAR observations is of significant importance for in-season monitoring of crop growth. The PAI is correlated directly with canopy foliage and structure (Jonckheere et al., 2004), which is a valuable indicator of crop condition. The PAI estimation from the vegetation indices is achieved via linear regression. Other researchers (Becker-Reshef et al., 2010; Jiao et al., 2011; Kogan et al., 2013; Liao et al., 2018) have utilized linear regression for the operational scalability of remote sensing products for vegetation monitoring. In spite of their localized application, linear regression techniques are often the preferred approach owing to their limited data requirements and simplicity to implement. Conversely, a higherorder polynomial may lead to an over-fitting problem that would likely fail to generalize on the test data set. Nevertheless, considering that the correlations between the GRVI and PAI are high $(>0.80)$ for both the TR and DSR (Fig. 8 and 12), the application of linear regression would be a cost-effective approach for PAI estimation from the GRVI.

Independent samples are used for training and testing of the regression model. In total 118 samples (from 24 fields) and remaining 80 samples (from 16 fields) of DSR are used for training and validation, respectively. In the case of TR cultivation, 65 samples from 12 fields are used for training with the 
remaining 42 samples from 8 fields reserved for validation. It is important to note that the training and validation points are sampled from all phenological stages of rice. However, PAI values $<0.15 \mathrm{~m}^{2} \mathrm{~m}^{-2}$ are not considered for training and validation of the model as these samples are likely to be affected by the underlying soil at the very early plant growth stages.

A $\mathrm{k}$-fold ( $\mathrm{k}=3$ in this case) cross-validation is performed while estimating PAI from the radar vegetation indices. In the cross-validation experiment, the samples are split into multiple pairs of training and test sets. Here it is important to note that with multi-temporal observations for each in-situ sampling location, the split of the dataset is based on field numbers. Hence, random sampling from the entire temporal dataset is not desirable. The PAI estimation accuracy is assessed for both the DSR and TR cases, with each having three validation datasets (Table 2). Among them, the best result is taken for representation in Fig. 13 with a 1:1-plot for GRVI and RVI provided separately. The accuracy of the PAI retrieval is measured by the correlation coefficient $(r)$, Root Mean Square Error (RMSE), and Mean Absolute Error (MAE).

Table 2: Error estimates for PAI retrieval from GRVI using k-fold cross validation techniques for three validation dataset

\begin{tabular}{ccccc}
\hline \multirow{2}{*}{ Rice type } & Error estimates & $\begin{array}{c}\text { Validation } \\
\text { set-1 }\end{array}$ & $\begin{array}{c}\text { Validation } \\
\text { set-2 }\end{array}$ & $\begin{array}{c}\text { Validation } \\
\text { set-3 }\end{array}$ \\
\hline \multirow{2}{*}{ DSR } & r & 0.810 & 0.823 & 0.798 \\
& RMSE & 0.835 & 0.821 & 0.852 \\
& MAE & 0.779 & 0.787 & 0.801 \\
\hline \multirow{2}{*}{ TR } & r & 0.803 & 0.805 & 0.789 \\
& RMSE & 1.049 & 1.051 & 1.102 \\
& MAE & 0.834 & 0.836 & 0.857 \\
\hline
\end{tabular}

For GRVI, the estimated PAI closely follows the 1:1 line with $\mathrm{r}=0.82$, RMSE $=0.821 \mathrm{~m}^{2} \mathrm{~m}^{-2}$, and MAE $=0.787 \mathrm{~m}^{2} \mathrm{~m}^{-2}$ for DSR. The errors of 

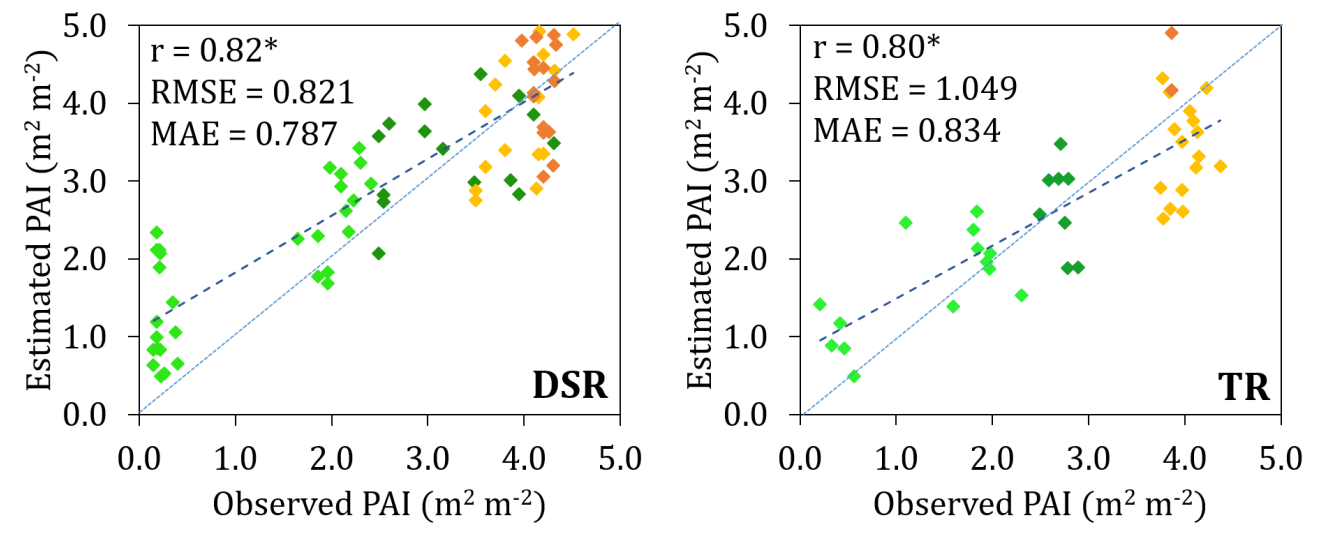

(a) PAI estimates from GRVI
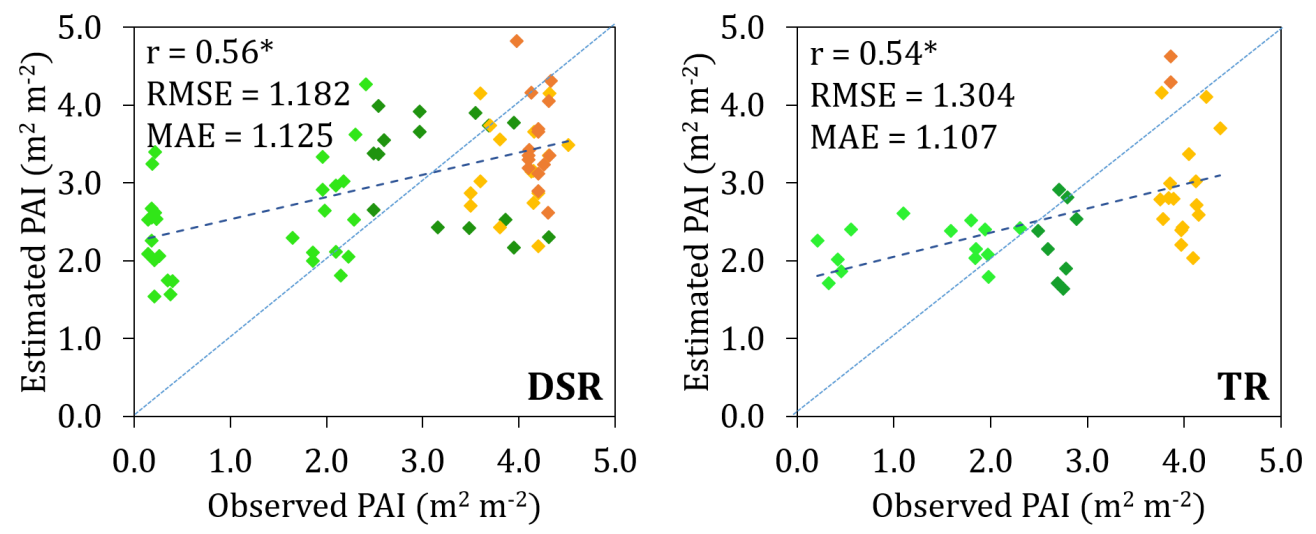

(b) PAI estimates from RVI

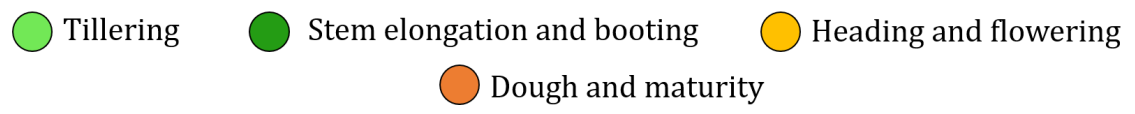

Figure 13: Validation of retrieved and observed Plant Area Index (PAI, $\mathrm{m}^{2} \mathrm{~m}^{-2}$ ) retrieval for direct seeded rice (DSR) and transplanted rice (TR) using radar vegetation indices (GRVI and RVI). Samples from several phenological stages are highlighted in different colours. The correlation coefficient $(r)$ values are significant with $\mathrm{p}$-value $<0.05$ for all these four cases.

estimation are comparatively higher $\left(\mathrm{RMSE}=1.049 \mathrm{~m}^{2} \mathrm{~m}^{-2}\right.$, and MAE $=$ $\left.0.834 \mathrm{~m}^{2} \mathrm{~m}^{-2}\right)$ in the case of TR. In comparison to GRVI, the errors associated with estimates of PAI are higher when using RVI, regardless of rice 
type. Correlation coefficients are also low for both DSR $(r=0.56)$ and TR $(r=0.54)$ cases. Higher dispersion of PAI estimates are observed with RVI throughout the entire range. This estimation error with PAI may have propagated from the training phase of the linear regression model between RVI and PAI.

Although PAI is more accurately estimated using GRVI, overestimation occurs in the early vegetative stages of both the rice types. At this early stage, the backscatter response is dominated by soil moisture due to low leaf area (Ulaby et al., 1984). This phenomenon is also reported for PAI estimation in the early stages of wheat (Mandal et al., 2019a; Ratha et al. 2019). On the other hand, the estimation accuracy of PAI derived from GRVI improves during more advanced stages, e.g., tillering to booting stage. At a high canopy density, this improved performance is likely due to the dominant volume scattering component generated from multiple interactions of the radar wave with stems, leaves, and the underlying soil (Brown et al. 2003).

\section{Conclusion}

The potential of using the Generalized volume scattering model based Radar Vegetation Index (GRVI) for determining rice growth condition from C-band SAR has been examined in this research. The temporal analysis of the GRVI derived from quad-pol RADARSAT-2 data suggests that this vegetation index follows crop growth development, i.e., increasing as the Plant Area Index (PAI) of rice increases. Correlation analysis is performed between the radar vegetation indices (RVI and GRVI) and PAI using samples 
from several phenological stages of rice. These results indicate that GRVI is highly correlated with rice development, as compared to RVI. Unlike RVI, the GRVI follows the advancement of plant growth stages until full canopy development, and as plant area accumulates. In addition, the dynamic range of RVI is less than that of GRVI when rice advances from an early vegetative to heading stage. It also confirms the improved characterization potential of GRVI compared to RVI. Qualitatively, the improved range and sensitivity of GRVI to rice development is observed in the spatio-temporal maps produced using this index. PAI is accurately estimated using a linear regression model for GRVI with promising error estimates for both the Direct Seeded Rice (DSR) and Transplanted Rice (TR). The correlation between the observed and estimated PAI from the GRVI-PAI linear regression model indicates a higher correlation coefficient $(r>0.80)$ for both rice type. The error estimates (RMSE and MAE) are also lower than that of the PAI estimates from an RVI-PAI model. Moreover, unlike RVI, the GRVI is able to distinguish between DSR and TR fields.

The application of GRVI, derived from C-band quad-pol SAR data, would be of interest for operational monitoring of rice production. Due to its simplistic and tractable formulation, the GRVI could be implemented at larger spatial scales. However, a reduced swath coverage and temporal revisit frequency associated with these quad-pol measurements would challenge operational activity. Nonetheless, a similar concept for the derivation of vegetation index based on the geodesic distance can be extended for dual and compactpol SAR data. Considering the operational missions of Sentinel-1, NISAR, RCM, SAOCOM, and upcoming RISAT-1A, it would be important to devise 
a proxy for vegetation growth indicators with geodesic distance-based indices for these imaging modes.

Considering the results presented here, a SAR-based vegetation index could provide an essential source of data for rice growth monitoring, in regions where optical data acquisitions are hindered due to persistent cloud cover. Further testing of this index is warranted and could be accomplished under a collaborative framework for cross-site experiment setups like the SAR intercomparison experiment within the Joint Experiment for Crop Assessment and Monitoring (JECAM) network and the Asian Rice Crop Estimation and Monitoring (Asia-RiCE) initiatives.

Disclosures

No potential conflict of interest is reported by the authors.

\section{Acknowledgment}

The authors would like to thank the Canadian Space Agency and MAXAR Technologies Ltd. (formerly MDA) for providing RADARSAT-2 images through the Joint Experiment for Crop Assessment and Monitoring (JECAM) Network. This work was partially supported by the Spanish Ministry of Science, Innovation and Universities, the State Agency of Research (AEI) and the European Funds for Regional Development (EFRD) under Project TEC2017-85244-C2-1-P. Authors are also thankful to Andhra Pradesh Space Application Centre (APSAC), ITE \& C Department, Government of Andhra Pradesh for support during field campaigns. 


\section{References}

Antropov, O., Rauste, Y., Hame, T., 2011. Volume scattering modeling in PolSAR decompositions: Study of ALOS PALSAR data over boreal forest. IEEE Transactions on Geoscience and Remote Sensing 49 (10), 3838-3848.

APAgriculture, 2018. Annual administration report 2016-17. Tech. Rep. 2016-2017, Department of Agriculture, Andhra Pradesh. URL http://www.apagrisnet.gov.in/2018/Admin/Annual\% 20Administrative\%20Report\%202016-17.pdf

Balasubramanian, V., Hill, J., 2002. Direct seeding of rice in Asia: emerging issues and strategic research needs for the 21st century. Direct seeding: Research strategies and opportunities, 15-39.

Becker-Reshef, I., Vermote, E., Lindeman, M., Justice, C., 2010. A generalized regression-based model for forecasting winter wheat yields in Kansas and Ukraine using MODIS data. Remote Sensing of Environment 114 (6), $1312-1323$.

Blaes, X., Defourny, P., Wegmuller, U., Della Vecchia, A., Guerriero, L., Ferrazzoli, P., 2006. C-band polarimetric indexes for maize monitoring based on a validated radiative transfer model. IEEE Trans. Geosci. Remote Sens. 44 (4), 791-800.

Bleiholder, H., Weber, E., Lancashire, P., Feller, C., Buhr, L., Hess, M., Wicke, H., Hack, H., Meier, U., Klose, R., et al., 2001. Growth stages of mono-and dicotyledonous plants, BBCH monograph. Federal Biologi- 
cal Research Centre for Agriculture and Forestry, Berlin/Braunschweig, Germany, 158.

Bouvet, A., Le Toan, T., Lam-Dao, N., 2009. Monitoring of the rice cropping system in the Mekong Delta using ENVISAT/ASAR dual polarization data. IEEE Transactions on Geoscience and Remote Sensing 47 (2), 517526.

Brown, S. C., Quegan, S., Morrison, K., Bennett, J. C., Cookmartin, G., 2003. High-resolution measurements of scattering in wheat canopiesimplications for crop parameter retrieval. IEEE Transactions on Geoscience and Remote Sensing 41 (7), 1602-1610.

Cabangon, R., Tuong, T. P., Abdullah, N., 2002. Comparing water input and water productivity of transplanted and direct-seeded rice production systems. Agricultural Water Management 57 (1), 11-31.

Cable, J., Kovacs, J., Jiao, X., Shang, J., 2014. Agricultural monitoring in northeastern Ontario, Canada, using multi-temporal polarimetric RADARSAT-2 data. Remote Sens. 6 (3), 2343-2371.

Canisius, F., Shang, J., Liu, J., Huang, X., Ma, B., Jiao, X., Geng, X., Kovacs, J. M., Walters, D., 2018. Tracking crop phenological development using multi-temporal polarimetric Radarsat-2 data. Remote Sensing of Environment $210,508-518$.

Chakraborty, M., Manjunath, K., Panigrahy, S., Kundu, N., Parihar, J., 2005. Rice crop parameter retrieval using multi-temporal, multi-incidence 
angle Radarsat SAR data. ISPRS Journal of Photogrammetry and Remote Sensing 59 (5), 310-322.

Choudhury, I., Chakraborty, M., 2006. SAR signature investigation of rice crop using RADARSAT data. International Journal of Remote Sensing $27(3), 519-534$.

De Bernardis, C. G., Vicente-Guijalba, F., Martinez-Marin, T., LopezSanchez, J. M., 2015. Estimation of key dates and stages in rice crops using dual-polarization SAR time series and a particle filtering approach. IEEE Journal of Selected Topics in Applied Earth Observations and Remote Sensing 8 (3), 1008-1018.

Fikriyah, V. N., Darvishzadeh, R., Laborte, A., Khan, N. I., Nelson, A., 2019. Discriminating transplanted and direct seeded rice using Sentinel-1 intensity data. International Journal of Applied Earth Observation and Geoinformation 76, 143-153.

He, Z., Li, S., Wang, Y., Dai, L., Lin, S., 2018. Monitoring rice phenology based on backscattering characteristics of multi-temporal RADARSAT-2 datasets. Remote Sensing 10 (2), 340.

Huang, Y., Walker, J. P., Gao, Y., Wu, X., Monerris, A., Feb 2016. Estimation of vegetation water content from the radar vegetation index at L-Band. IEEE Trans. Geosci. Remote Sens. 54 (2), 981-989.

Inoue, Y., Kurosu, T., Maeno, H., Uratsuka, S., Kozu, T., DabrowskaZielinska, K., Qi, J., 2002. Season-long daily measurements of multifrequency (Ka, Ku, X, C, and L) and full-polarization backscatter signatures 
over paddy rice field and their relationship with biological variables. Remote Sensing of Environment 81 (2-3), 194-204.

Inoue, Y., Sakaiya, E., Wang, C., 2014. Capability of C-band backscattering coefficients from high-resolution satellite SAR sensors to assess biophysical variables in paddy rice. Remote Sensing of Environment 140, 257-266.

INRA, 2017. CAN-EYE.

URL https://www6.paca.inra.fr/can-eye

Jagdhuber, T., Hajnsek, I., Bronstert, A., Papathanassiou, K. P., 2012. Soil moisture estimation under low vegetation cover using a multi-angular polarimetric decomposition. IEEE Transactions on Geoscience and Remote Sensing 51 (4), 2201-2215.

Jiao, X., McNairn, H., Shang, J., Pattey, E., Liu, J., Champagne, C., 2011. The sensitivity of RADARSAT-2 polarimetric SAR data to corn and soybean leaf area index. Canadian Journal of Remote Sensing 37 (1), 69-81.

Jonckheere, I., Fleck, S., Nackaerts, K., Muys, B., Coppin, P., Weiss, M., Baret, F., 2004. Review of methods for in situ leaf area index determination: Part I. Theories, sensors and hemispherical photography. Agricultural and forest meteorology 121 (1-2), 19-35.

Kim, Y., Jackson, T., Bindlish, R., Hong, S., Jung, G., Lee, K., 2014. Retrieval of wheat growth parameters with radar vegetation indices. IEEE Geosci. Remote Sens. Lett. 11 (4), 808-812.

Kim, Y., Jackson, T., Bindlish, R., Lee, H., Hong, S., 2012. Radar vegetation 
index for estimating the vegetation water content of rice and soybean. IEEE Geosci. Remote Sens. Lett. 9 (4), 564-568.

Kim, Y., van Zyl, J. J., Aug 2009. A time-series approach to estimate soil moisture using polarimetric radar data. IEEE Trans. Geosci. Remote Sens. 47 (8), 2519-2527.

Kogan, F., Kussul, N., Adamenko, T., Skakun, S., Kravchenko, O., Kryvobok, O., Shelestov, A., Kolotii, A., Kussul, O., Lavrenyuk, A., 2013. Winter wheat yield forecasting in ukraine based on earth observation, meteorological data and biophysical models. International Journal of Applied Earth Observation and Geoinformation 23, 192-203.

Kuenzer, C., Knauer, K., 2013. Remote sensing of rice crop areas. International Journal of Remote Sensing 34 (6), 2101-2139.

Kumar, V., Kumari, M., Saha, S. K., 2013. Leaf area index estimation of lowland rice using semi-empirical backscattering model. Journal of Applied Remote Sensing 7 (1), 073474.

Kumar, V., Rao, Y., 2015. Temporal analysis of different crops using quad-pol RADARSAT-2 data. In: 2015 IEEE International Geoscience and Remote Sensing Symposium (IGARSS). IEEE, pp. 3211-3214.

Lampayan, R., Faronilo, J., Tuong, T., Espiritu, A., de Dios, J., Bayot, R., Bueno, C., Hosen, Y., 2015. Effects of seedbed management and delayed transplanting of rice seedlings on crop performance, grain yield, and water productivity. Field Crops Research 183, 303-314. 
Le Toan, T., Ribbes, F., Wang, L.-F., Floury, N., Ding, K.-H., Kong, J. A., Fujita, M., Kurosu, T., 1997. Rice crop mapping and monitoring using ERS-1 data based on experiment and modeling results. IEEE Transactions on Geoscience and Remote Sensing 35 (1), 41-56.

Li, K., Brisco, B., Yun, S., Touzi, R., 2012. Polarimetric decomposition with RADARSAT-2 for rice mapping and monitoring. Canadian Journal of Remote Sensing 38 (2), 169-179.

Liao, C., Wang, J., Shang, J., Huang, X., Liu, J., Huffman, T., 2018. Sensitivity study of Radarsat-2 polarimetric SAR to crop height and fractional vegetation cover of corn and wheat. International journal of remote sensing 39 (5), 1475-1490.

Lopez-Sanchez, J. M., Ballester-Berman, J. D., Hajnsek, I., 2011. First results of rice monitoring practices in spain by means of time series of terrasar-x dual-pol images. IEEE Journal of selected topics in applied earth observations and remote sensing 4 (2), 412-422.

Lopez-Sanchez, J. M., Cloude, S. R., Ballester-Berman, J. D., 2012. Rice phenology monitoring by means of SAR polarimetry at X-band. IEEE Transactions on Geoscience and Remote Sensing 50 (7), 2695-2709.

Lopez-Sanchez, J. M., Vicente-Guijalba, F., Ballester-Berman, J. D., Cloude, S. R., 2014. Polarimetric response of rice fields at C-band: Analysis and phenology retrieval. IEEE Transactions on Geoscience and Remote Sensing $52(5), 2977-2993$. 
Mahajan, G., Bharaj, T., Timsina, J., 2009. Yield and water productivity of rice as affected by time of transplanting in Punjab, India. Agricultural Water Management 96 (3), 525-532.

Mahajan, G., Chauhan, B., Gill, M., 2013. Dry-seeded rice culture in Punjab State of India: lessons learned from farmers. Field Crops Research 144, 89 99.

Mandal, D., Kumar, V., Bhattacharya, A., Rao, Y. S., Siqueira, P., Bera, S., Dec 2018. Sen4Rice: A processing chain for differentiating early and late transplanted rice using time-series Sentinel-1 SAR data with Google Earth Engine. IEEE Geoscience and Remote Sensing Letters 15 (12), 1947-1951.

Mandal, D., Kumar, V., McNairn, H., Bhattacharya, A., Rao, Y., 2019a. Joint estimation of plant area index (PAI) and wet biomass in wheat and soybean from C-band polarimetric SAR data. International Journal of Applied Earth Observation and Geoinformation 79, 24-34.

Mandal, D., Kumar, V., Rao, Y., Bhattacharya, A., Ramana, K., 2019b. Experimental field campaigns at Vijayawada test site. Tech. Rep. MRS2019TR02, Microwave Remote Sensing Lab, India.

URL http://doi .org/10.17605/OSF. IO/DN3E8

McNairn, H., Jiao, X., Pacheco, A., Sinha, A., Tan, W., Li, Y., 2018. Estimating canola phenology using synthetic aperture radar. Remote sensing of environment 219, 196-205.

McNairn, H., Shang, J., 2016. A review of multitemporal synthetic aper- 
ture radar (SAR) for crop monitoring. In: Multitemporal Remote Sensing. Springer, pp. 317-340.

Nelson, A., Setiyono, T., Rala, A., Quicho, E., Raviz, J., Abonete, P., Maunahan, A., Garcia, C., Bhatti, H., Villano, L., et al., 2014. Towards an operational SAR-based rice monitoring system in Asia: Examples from 13 demonstration sites across Asia in the RIICE project. Remote Sensing 6 (11), 10773-10812.

NIBIO, 2012. Direct seeded rice (semidry): Adaptation technology for climate change in semi arid regions. Tech. rep., Norwegian Institute of Bioeconomy Research.

URL https://www.nibio.no/en/projects/ climaadapt/technical-briefs/_/attachment/ inline/89cf553b-6cd4-4235-871d-1fa499f41129: 38c7a651d4912d44b047101fd7f1eea0cef45ece/DSR\%20PROOF\%20FINAL . pdf

Oyoshi, K., Tomiyama, N., Okumura, T., Sobue, S., Sato, J., 2016. Mapping rice-planted areas using time-series synthetic aperture radar data for the Asia-RiCE activity. Paddy and water environment 14 (4), 463-472.

Phan, H., Le Toan, T., Bouvet, A., Nguyen, L., Pham Duy, T., Zribi, M., 2018. Mapping of rice varieties and sowing date using X-Band SAR data. Sensors 18 (1), 316.

Rao, V., Rao, B., Venkateswarlu, B., 2013. Agroclimatic atlas of Andhra Pradesh. Tech. Rep. 978-93-80883-27-4, Central Research Institute for 
Dryland Agriculture, Hyderabad.

URL http://www.cropweatheroutlook.in/crida/amis/ Agroclimatic\%20Atlas $\% 20$ of $\% 20 \mathrm{AP}$.pdf

Ratha, D., Bhattacharya, A., Frery, A. C., Jan 2018. Unsupervised classification of polsar data using a scattering similarity measure derived from a geodesic distance. IEEE Geoscience and Remote Sensing Letters 15 (1), 151-155.

Ratha, D., De, S., Celik, T., Bhattacharya, A., July 2017. Change detection in polarimetric SAR images using a geodesic distance between scattering mechanisms. IEEE Geosci. Remote Sens. Lett. 14 (7), 1066-1070.

Ratha, D., Gamba, P., Bhattacharya, A., Frery, A. C., 2019. Novel techniques for built-up area extraction from polarimetric SAR images. IEEE Geoscience and Remote Sensing Letters, 1-5.

Ratha, D., Mandal, D., Kumar, V., McNairn, H., Bhattacharya, A., Frery, A. C., 2019. A generalized volume scattering model-based vegetation index from polarimetric SAR data. IEEE Geoscience and Remote Sensing Letters 16 (11), 1791-1795.

Rossi, C., Erten, E., 2014. Paddy-rice monitoring using tandem-x. IEEE Transactions on Geoscience and Remote Sensing 53 (2), 900-910.

Sato, A., Yamaguchi, Y., Singh, G., Park, S.-E., 2011. Four-component scattering power decomposition with extended volume scattering model. IEEE Geoscience and Remote Sensing Letters 9 (2), 166-170. 
Singh, K., Gajri, P., Arora, V., 2001. Modelling the effects of soil and water management practices on the water balance and performance of rice. Agricultural Water Management 49 (2), 77-95.

Singha, M., Dong, J., Zhang, G., Xiao, X., 2019. High resolution paddy rice maps in cloud-prone Bangladesh and Northeast India using Sentinel-1 data. Scientific data $6(1), 26$.

Slade, B., 2018. Radarsat-2 product description. RN-SP-52-1238 (1/14).

URL https://mdacorporation.com/docs/default-source/

a technical-documents/geospatial-services/52-1238_rs2_product_ description.pdf?sfvrsn=10

Steele-Dunne, S. C., McNairn, H., Monsivais-Huertero, A., Judge, J., Liu, P., Papathanassiou, K., 2017. Radar remote sensing of agricultural canopies: A review. IEEE Journal of Selected Topics in Applied Earth Observations and Remote Sensing 10 (5), 2249-2273.

Torbick, N., Chowdhury, D., Salas, W., Qi, J., 2017. Monitoring rice agriculture across myanmar using time series Sentinel- 1 assisted by Landsat- 8 and PALSAR-2. Remote Sensing 9 (2), 119.

Ulaby, F., Allen, C., Eger, G., Kanemasu, E., 1984. Relating the microwave backscattering coefficient to leaf area index. Remote Sensing of Environment 14 (1-3), 113-133.

van Zyl, J. J., 2011. Synthetic aperture radar polarimetry. Vol. 2. John Wiley \& Sons. 
Vicente-Guijalba, F., Martinez-Marin, T., Lopez-Sanchez, J. M., 2014. Crop phenology estimation using a multitemporal model and a Kalman filtering strategy. IEEE Geoscience and Remote Sensing Letters 11 (6), 1081-1085.

Wang, C., Wu, J., Zhang, Y., Pan, G., Qi, J., Salas, W. A., 2009. Characterizing L-band scattering of paddy rice in southeast China with radiative transfer model and multitemporal ALOS/PALSAR imagery. IEEE Transactions on Geoscience and Remote Sensing 47 (4), 988-998.

Wang, H., Magagi, R., Goita, K., 2016. Polarimetric decomposition for monitoring crop growth status. IEEE Geoscience and Remote Sensing Letters $13(6), 870-874$.

Weiss, M., Baret, F., Smith, G., Jonckheere, I., Coppin, P., 2004. Review of methods for in situ leaf area index (LAI) determination: Part II. Estimation of LAI, errors and sampling. Agricultural and forest meteorology $121(1-2), 37-53$.

Wiseman, G., McNairn, H., Homayouni, S., Shang, J., 2014. RADARSAT2 polarimetric SAR response to crop biomass for agricultural production monitoring. IEEE Journal of Selected Topics in Applied Earth Observations and Remote Sensing 7 (11), 4461-4471.

Xie, Q., Ballester-Berman, J., Lopez-Sanchez, J., Zhu, J., Wang, C., 2017. On the use of generalized volume scattering models for the improvement of general polarimetric model-based decomposition. Remote Sensing 9 (2), 117. 
771 Yang, Z., Li, K., Liu, L., Shao, Y., Brisco, B., Li, W., 2014. Rice growth mon772 itoring using simulated compact polarimetric C band SAR. Radio Science $77349(12), 1300-1315$.

774 Yang, Z., Shao, Y., Li, K., Liu, Q., Liu, L., Brisco, B., 2017. An improved 775 scheme for rice phenology estimation based on time-series multispectral

776

777 HJ-1A/B and polarimetric RADARSAT-2 data. Remote sensing of environment 195, 184-201.

Yuzugullu, O., Erten, E., Hajnsek, I., 2015. Rice growth monitoring by means of X-band co-polar SAR: Feature clustering and BBCH scale. IEEE Geoscience and Remote Sensing Letters 12 (6), 1218-1222.

Yuzugullu, O., Erten, E., Hajnsek, I., 2018. Assessment of paddy rice height: Sequential inversion of coherent and incoherent models. IEEE Journal of Selected Topics in Applied Earth Observations and Remote Sensing 11 (9), 3001-3013.

Yuzugullu, O., Marelli, S., Erten, E., Sudret, B., Hajnsek, I., 2017. Determining rice growth stage with X-band SAR: A metamodel based inversion. Remote Sensing 9 (5), 460. 